\title{
Gold Nanofilm Redox Catalysis for Oxygen Reduction at Soft Interfaces
}

\author{
Evgeny Smirnov, ${ }^{a}$ Pekka Peljo, ${ }^{a}$ Micheál D. Scanlon ${ }^{a, b}$ and Hubert. H. Girault ${ }^{a}{ }^{*}$
}

${ }^{a}$ Laboratoire d'Electrochimie Physique et Analytique (LEPA), École Polytechnique Fédérale de Lausanne (EPFL), Valais Wallis, Rue de l'Industrie 17, Case Postale 440, 1951 Sion, Switzerland.

${ }^{b}$ Department of Chemistry, the Tyndall National Institute and the Analytical and Biological Chemistry Research Facility (ABCRF), University College Cork, Cork, Ireland.

\section{Corresponding Author}

*E-mail: $\underline{\text { Hubert.Girault@epfl.ch }}$ 


\begin{abstract}
Functionalization of a soft or liquid-liquid interface by a one gold nanoparticle thick "nanofilm" provides a conductive pathway to facilitate interfacial electron transfer from a lipophilic electron donor to a hydrophilic electron acceptor in a process known as interfacial redox catalysis. The gold nanoparticles in the nanofilm are charged by Fermi level equilibration with the lipophilic electron donor and act as an interfacial reservoir of electrons. Additional thermodynamic driving force can be provided by electrochemically polarising the interface. Using these principles, the biphasic reduction of oxygen by a lipophilic electron donor, decamethylferrocene, dissolved in $\alpha, \alpha, \alpha$-trifluorotoluene was catalysed at a gold nanoparticle nanofilm modified water-oil interface. A recently developed microinjection technique was utilised to modify the interface reproducibly with the mirror-like gold nanoparticle nanofilm, while the oxidised electron donor species and the reduction product, hydrogen peroxide, were detected by ion transfer voltammetry and UV/vis spectroscopy, respectively. Metallization of the soft interface allowed the biphasic oxygen reduction reaction to proceed via an alternative mechanism with enhanced kinetics and at a significantly lower overpotential in comparison to a bare soft interface. Weaker lipophilic reductants, such as ferrocene, were capable of charging the interfacial gold nanoparticle nanofilm but did not have sufficient thermodynamic driving force to significantly elicit biphasic oxygen reduction.
\end{abstract}

KEYWORDS: gold nanoparticles, soft interfaces, electron transfer, electrocatalysis, oxygen reduction reaction. 


\section{INTRODUCTION}

An interface between two immiscible electrolyte solutions (ITIES) or a "soft" interface is an attractive platform at which to assemble nanoparticles (NPs) due to its electrochemical polarisability, inherent defect-free nature, mechanical flexibility and the ease with which NPs may be manipulated and precisely tuned therein [1-8]. A burgeoning area of research is concerned with the biphasic electrocatalysis of redox reactions of interest for energy research, including the oxygen $\left(\mathrm{O}_{2}\right)$ reduction reaction $(\mathrm{ORR})$ [9-19] and the hydrogen $\left(\mathrm{H}_{2}\right)$ evolution reaction (HER) [20-28], using soft interfaces functionalized with molecular species, metallic NPs or inorganic non-precious metal-based materials. The use of adsorbed solid particulate electrocatalysts at electrochemically polarisable soft interfaces has recently been reviewed by Dryfe and co-workers [29].

Whereas several reports have highlighted the catalysis of biphasic reactions by (i) facilitating the transfer of protons [12, 30, 31], or other ions [17], across the soft interface and (ii) the use of interfacial species, either molecular $[12,32,33]$ or solid particulates $[22,26]$, to coordinate reactants to enable electrocatalysis, far less common is (iii) the use of NPs as bipolar electrodes to facilitate catalysis via direct interfacial electron transfer (IET) between a lipophilic electron donor and a hydrophilic electron acceptor or vice versa [8]. Such a process is termed interfacial redox catalysis.

The nature of an adsorbed metallic NP in terms of its ability to store or discharge electrons significantly influences its effectiveness to facilitate interfacial redox catalysis. Gold NPs (AuNPs) can be regarded as multivalent redox species with a wide range of oxidation states that may be charged or discharged by Fermi level equilibration with redox couples in solution [34]. Recently, we highlighted the use of soft interfaces functionalized with one AuNP thick "nanofilms" to catalyse IET between a lipophilic electron donor (D) redox couple, ferrocenium cation/ ferrocene $\left(\mathrm{Fc}^{+/ 0}\right)$, and a hydrophilic electron acceptor (A) redox couple, ferri/ferrocyanide $\left(\left[\mathrm{Fe}(\mathrm{CN})_{6}\right]^{3-/ 4-}\right)$ [8]. Similarly, Dryfe and co-workers catalysed IET between the same lipophilic electron donor and hydrophilic electron acceptor redox couples by functionalizing the soft interface with adsorbed conductive carbon nanomaterials, such as few-layer graphene and carbon nanotubes [35]. Furthermore, they exploited IET mediated by these adsorbed carbon nanomaterials to functionalize the latter with metallic NPs by in situ electrodeposition at the soft interface [35-37]. Finally, in situ generated reduced graphene oxide (RGO) at soft interfaces was shown to facilitate IET and enhance the kinetics of biphasic $\mathrm{O}_{2}$ reduction in the presence of lipophilic electron donors [18]. 
Herein, we demonstrate that AuNP nanofilms catalyse IET across a soft interface from an electron donor in the organic phase to $\mathrm{O}_{2}$ dissolved in the aqueous phase, allowing biphasic $\mathrm{O}_{2}$ reduction to proceed via an alternative mechanism with a much lower overpotential to that reported at bare soft interfaces. $\mathrm{O}_{2}$ is biphasically reduced to $\mathrm{H}_{2} \mathrm{O}_{2}$, followed by further reduction or decomposition of the latter to water. Voltammetry studies revealed that while both strong, i.e., decamethlyferrocene (DMFc), and weak, i.e., Fc, lipophilic electron donors were capable of injecting electrons into the AuNP nanofilm, thereby charging it, only DMFc was capable of significantly reducing aqueous $\mathrm{O}_{2}$ by interfacial redox catalysis. The latter is discussed in terms of Fermi level equilibration of the redox couples in solution with the AuNPs at the soft interface.

\section{EXPERIMENTAL}

\subsection{Chemicals.}

All chemicals were used as received without further purification. All aqueous solutions were prepared with ultra-pure water (Millipore Milli-Q, specific resistivity $18.2 \mathrm{M} \Omega \cdot \mathrm{cm}$ ). Bis(triphenylphosphoranylidene)ammonium chloride (BACl, 98\%), tetrapropylammonium chloride (TPropACl, 98\%), $\mathrm{LiCl},>99 \%, \mathrm{LiOH} \cdot \mathrm{H}_{2} \mathrm{O}, \mathrm{HCl}(32 \%$ solution) and ferrocene (Fc, 98\%) were purchased from Fluka. Lithium tetrakis(pentafluorophenyl)borate ethyl etherate (LiTB-DEE purum) was purchased from Boulder Scientific. Hydrogen tetrachloroaurate(III) hydrate $\left(\mathrm{HAuCl}_{4} \cdot 3 \mathrm{H}_{2} \mathrm{O}, 99.999 \%, 49 \% \mathrm{Au}\right)$, and decamethylferrocene (DMFc, 99\%) were provided by Alfa Aesar. Silver nitrate $\left(\mathrm{AgNO}_{3}, 99 \%\right)$ was bought from Chempur and ascorbic acid $\left(\mathrm{C}_{6} \mathrm{H}_{8} \mathrm{O}_{6}\right)$ from Reidel-de-Haem. Trisodium citrate dihydrate $\left(\mathrm{Na}_{3} \mathrm{C}_{6} \mathrm{H}_{5} \mathrm{O}_{7} \cdot 2 \mathrm{H}_{2} \mathrm{O}, 98 \%\right)$, tetrathiafulvalene (TTF, $\geq 99 \%$ ) and the organic solvent $\alpha, \alpha, \alpha$-trifluorotoluene (TFT, 99\%+) were purchased from Acros. Bis(triphenylphosphoranylidene) ammonium tetrakis(pentafluorophenyl)borate (BATB) was prepared by metathesis, as described previously $[38]$.

\subsection{Functionalization of the soft interface with a AuNP nanofilm.}

Citrate-stabilised colloidal AuNP solutions were synthesised by either Turkevich and Fren's method [39, 40], for $12 \mathrm{~nm}$ mean diameter NPs, or Park's method [2], for $38 \mathrm{~nm}$ mean diameter NPs. Comprehensive details of the synthesis and characterisation of both colloidal AuNP solutions used herein are available in reference [8]. Additionally, the methodology 
required to functionalize the water|TFT interface in a 4-electrode electrochemical cell with a flat mirror-like nanofilm of AuNPs (see Figure 1A) by controlled interfacial microinjection of methanol suspended AuNPs to the vicinity of the interface was described in detail previously [8].

\subsection{Electrochemical measurements.}

Cyclic voltammograms (CVs) at bare and AuNP nanofilm functionalized water|TFT interfaces were recorded in duplicate under both ambient aerobic conditions and anaerobic conditions using a PGSTAT101 (Metrohm, Netherlands) potentiostat and a four-electrode electrochemical cell. Anaerobic conditions were achieved using a nitrogen filled glove box. Also, CVs were recorded in a configuration whereby the aqueous and organic phases were

physically separated but electrically connected by $3 \mathrm{~mm}$ diameter gold disk electrodes, enabling the selective observation of electron transfer alone across the interface without interference from ion transfer. This is a variant of the "electronic conductor separating the oil-water interface" (ECSOW) configuration reported by Osakai for studying simple electron transfer processes at the ITIES without interference from ion transfer [41]. The electrochemical cell configurations used are outlined in Figure $1 \mathrm{~B}$ and $\mathrm{C}$. The effect of $\mathrm{pH}$ on the interfacial electron transfer was studied by tuning the initial $\mathrm{pH}$ value in the aqueous phase of the electrochemical cell depicted in Figure $1 \mathrm{~B}$ by addition of freshly prepared $\mathrm{HCl}$ or $\mathrm{LiOH}$ solutions with final concentrations of 1 $\mathrm{mM}$ each. This resulted in $\mathrm{pH}$ values of $c a .3$ and 11 , respectively.

\section{4. "Shake-flask" experiments to quantify biphasic $\mathrm{H}_{2} \mathrm{O}_{2}$ generation.}

A shake-flask experiment was designed (see Figure 1D) to (i) identify if the biphasic $\mathrm{O}_{2}$ reduction product $\mathrm{H}_{2} \mathrm{O}_{2}$ was formed and, if so, (ii) quantify the amount of $\mathrm{H}_{2} \mathrm{O}_{2}$ generated as a result of interfacial redox catalysis in the presence of a AuNP nanofilm. A sub-monolayer film of $38 \mathrm{~nm}$ mean diameter AuNPs with a similar AuNP surface coverage to that investigated electrochemically by CV was self-assembled at the water|TFT interface, as described previously [7], with some minor adjustments. Firstly, to minimise the influence of tetrathiafulvalene (TTF; $0.18 \mathrm{mM}$ ) on the biphasic $\mathrm{O}_{2}$ reduction, the DMFc concentration in the TFT organic phase was approximately 20 times higher $(4 \mathrm{mM})$. Then, once a large droplet of TFT was functionalized with a AuNP nanofilm, a $1 \mathrm{mM}$ aqueous LiTB-DEE solution was added to the shake-flask, followed by stirring for 5 minutes. Partition of hydrophobic $\mathrm{TB}^{-}$polarised the soft interface 
positively to $c a$. $0.6 \mathrm{~V}[12,42]$. After 5 minutes the TFT phase turned green, indicating the generation of $\mathrm{DMFc}^{+}$. The mixture was immediately transferred to a polypropylene tube and centrifuged at 2000 RPM for 10 minutes in order to obtain complete phase separation. The amount of $\mathrm{H}_{2} \mathrm{O}_{2}$ produced and present in the aqueous phase was analysed by the iodide method, as described in detail previously [18], and the \% conversion of $\mathrm{DMFc}$ to $\operatorname{DMFc}^{+}\left(\lambda_{\max }=779 \mathrm{~nm}\right)$ was determined by UV/vis spectroscopy (the optical path was $1 \mathrm{~cm}$ ). The short timescale of the experiment minimised the influence of the uncatalysed ion transfer - electron transfer (IT - ET) biphasic ORR mechanism, discussed vide infra, as that reaction typically takes more than 30 minutes [43].

Figure 1. (A) Picture of a soft water|TFT interface in a 4-electrode electrochemical cell functionalized with a mirror-like nanofilm of AuNPs after interfacial microinjection of methanol suspended AuNPs (note the TFT phase on the bottom contains $1 \mathrm{mM} \mathrm{Fc}$ in this instance). Schematic representations of the compositions of the electrochemical cell configurations used for 4-electrode cyclic voltammetry measurements at (B) the ITIES and (C) with separated phases. (D) Schematic of the "shake-flask" experiment to determine the amount of $\mathrm{H}_{2} \mathrm{O}_{2}$ generated by interfacial redox catalysis.

\section{RESULTS AND DISCUSSION}

\subsection{Biphasic $\mathrm{O}_{2}$ reduction by the ion transfer - electron transfer mechanism.}

To date, the vast majority of biphasic $\mathrm{O}_{2}$ reduction studies have been carried out under acidic conditions involving an ion transfer - electron transfer (IT - ET) mechanism (see equations (1) and (2)) whereby the soft interface acts as proton pump, i.e., proton IT is initiated by varying the interfacial Galvani potential difference across the water|organic interface, $\Delta_{\mathrm{o}}^{\mathrm{w}} \phi$, externally using a potentiostat or chemically by distribution of a salt [19]. The ET reduction step then proceeds homogeneously with reduction of $\mathrm{O}_{2}$ dissolved in the organic phase by a suitable lipophilic electron donor, $\mathrm{D}_{\mathrm{o}}^{0}$; typically $\mathrm{TTF}$ or $\mathrm{Fc}$ and its derivatives, dimethylferrocene (DiMFc) and DMFc.

$2 \mathrm{H}_{\mathrm{w}}^{+} \stackrel{\mathrm{IT}}{\rightleftarrows} 2 \mathrm{H}_{\mathrm{o}}^{+}$ 


$$
2 \mathrm{D}_{\mathrm{o}}^{0}+2 \mathrm{H}_{\mathrm{o}}^{+}+\mathrm{O}_{2, \mathrm{o}} \stackrel{\mathrm{ET}}{\longrightarrow} 2 \mathrm{D}_{\mathrm{o}}^{+}+\mathrm{H}_{2} \mathrm{O}_{2, \mathrm{o}}
$$

where $\mathrm{w}$ and o denote the water and organic phases, respectively. The IT step can be catalysed by the presence of various aniline derivatives $[9,30]$ and free-base- or metalloporphyrins $[44$, 45], porphines [42] or phthalocyanines [31] in the organic phase and the desired reduction product $\left(\mathrm{H}_{2} \mathrm{O}\right.$ versus $\left.\mathrm{H}_{2} \mathrm{O}_{2}\right)$ can be favoured by interfacial assemblies of cobalt porphyrins [12, $32,33]$ or choice of electron donor [10].

Recently, biphasic $\mathrm{O}_{2}$ reduction has been achieved under neutral and alkaline conditions [17]. Therein, the ET reduction of organic solubilised $\mathrm{O}_{2}$ was facilitated by IT of hydrated metal cations $\left(\mathrm{M}^{+}\right)$across the soft interface (see equations (3) and (4)).

$$
\begin{aligned}
& {\left[\mathrm{M}\left(\mathrm{H}_{2} \mathrm{O}\right)_{m}\right]_{\mathrm{w}}^{+} \stackrel{\mathrm{IT}}{\rightleftarrows}\left[\mathrm{M}\left(\mathrm{H}_{2} \mathrm{O}\right)_{m}\right]_{\mathrm{o}}^{+}} \\
& 2 \mathrm{D}_{\mathrm{o}}^{0}+2\left[\mathrm{M}\left(\mathrm{H}_{2} \mathrm{O}\right)_{m}\right]_{\mathrm{o}}^{+}+\mathrm{O}_{2, \mathrm{o}} \stackrel{\mathrm{ET}}{\longrightarrow} 2 \mathrm{D}_{\mathrm{o}}^{+}+2\left[\mathrm{M}\left(\mathrm{H}_{2} \mathrm{O}\right)_{m-1}(\mathrm{OH})\right]_{\mathrm{o}}+\mathrm{H}_{2} \mathrm{O}_{2, \mathrm{o}}
\end{aligned}
$$

where $m$ is the number of water molecules within the metal ion hydration sphere. However, to initiate such an IT required a substantial positive polarisation of the soft interface $\left(\Delta_{\mathrm{o}}^{\mathrm{w}} \phi \approx+500\right.$ $\mathrm{mV})$ [17].

\subsection{Interfacial redox catalysis.}

Following on from our previous work on interfacial redox catalysis at AuNP nanofilm functionalized soft interfaces [8], this work focuses on interfacial redox catalysis of biphasic $\mathrm{O}_{2}$ reduction. The general mechanism for interfacial redox catalysis is:

$\mathrm{D}_{\mathrm{o}}^{0}+\mathrm{AuNP}_{\mathrm{int}}^{z} \rightleftarrows \mathrm{D}_{\mathrm{o}}^{n_{\mathrm{o}}}+\mathrm{AuNP}_{\mathrm{int}}^{z-n_{\mathrm{o}}}$

$$
\mathrm{A}_{\mathrm{w}}^{0}+\mathrm{AuNP}_{\mathrm{int}}^{z-n_{\mathrm{w}}} \rightleftarrows \mathrm{A}_{\mathrm{w}}^{-n_{\mathrm{w}}}+\mathrm{AuNP}_{\mathrm{int}}^{z}
$$

where $\mathrm{A}_{\mathrm{w}}^{0}$ is an aqueous electron acceptor $\left(\mathrm{O}_{2}\right.$ in experiments as discussed below), int denotes the interface, and $z$ is the charge on the AuNP. As we have shown previously, at equilibrium the Fermi level of the electrons in the aqueous redox couple $\left(E_{\mathrm{F}}^{\mathrm{W}}\right)$ is equal to that in the organic redox couple $\left(E_{\mathrm{F}}^{\mathrm{o}}\right) \cdot E_{\mathrm{F}}^{\mathrm{w}}$ is given by the Nernst equation and the Galvani potential of water (also called the inner potential; $\phi_{\mathrm{w}}$ ) on the absolute vacuum scale (AVS) taking the electron at rest in vacuum as the origin (in $\mathrm{kJ} \mathrm{mol}^{-1}$ ): 
$E_{\mathrm{F}}^{\mathrm{w}}=-F\left[\left[E_{\mathrm{A}_{\mathrm{w}}^{0} / \mathrm{A}_{\mathrm{w}}^{-}}^{0}\right]_{\mathrm{SHE}}^{\mathrm{w}}+\frac{R T}{n_{\mathrm{w}} F} \ln \left(\frac{c_{\mathrm{A}_{\mathrm{w}}^{0}}^{b}}{c_{\mathrm{A}_{\mathrm{w}}^{-}}^{b}}\right)+\phi_{\mathrm{w}}+\left[E_{\mathrm{H}^{+} / 1 / 2 \mathrm{H}_{2}}^{0}\right]_{\mathrm{AVS}}^{\mathrm{w}}\right]$

where $\left[E_{\mathrm{H}^{+} / 1 / 2 \mathrm{H}_{2}}^{0}\right]_{\mathrm{AVS}}^{\mathrm{w}}=4.44 \mathrm{~V}$ is the potential of the standard hydrogen electrode (SHE) on the $\mathrm{AVS},\left[E_{\mathrm{A}_{\mathrm{w}}^{0} / \mathrm{A}_{\mathrm{w}}^{-}}^{0}\right]_{\mathrm{SHE}}^{\mathrm{w}}$ is the standard redox potential of the aqueous electron acceptor, $n_{\mathrm{w}}$ is the number of electrons exchanged in equation (6), $c_{\mathrm{A}_{\mathrm{w}}^{0}}^{b}$ and $c_{\mathrm{A}_{\mathrm{w}}^{-}}^{b}$ are the bulk concentrations of the oxidized and reduced forms, respectively, of the electron acceptor in the aqueous solution and, finally, $\phi_{\mathrm{w}}$ the inner potential defined by $\phi_{\mathrm{w}}=\chi_{\mathrm{w}}+\psi_{\mathrm{w}}$, where $\chi_{\mathrm{w}}$ is the surface potential and $\psi_{\mathrm{w}}$ is the outer potential of the aqueous phase. Note that in ref. [8] the Fermi level of electrons was written similarly, $E_{F}^{o}$ being given by:

$E_{\mathrm{F}}^{\mathrm{o}}=-F\left[\left[E_{\mathrm{D}_{\mathrm{o}}^{+} / \mathrm{D}_{\mathrm{o}}^{0}}^{0}\right]_{\mathrm{SHE}}^{\mathrm{o}}+\frac{R T}{n_{\mathrm{o}} F} \ln \left(\frac{c_{\mathrm{D}_{\mathrm{o}}^{+}}^{b}}{c_{\mathrm{D}_{\mathrm{o}}^{0}}^{b}}\right)+\phi_{\mathrm{o}}+\left[E_{\mathrm{H}^{+} / 1 / 2 \mathrm{H}_{2}}^{0}\right]_{\mathrm{AVS}}^{\mathrm{w}}\right]$

By polarising the soft interface using an external power supply, i.e., varying $\Delta_{\mathrm{o}}^{\mathrm{w}} \phi, E_{\mathrm{F}}^{\mathrm{o}}$ is changed with respect to $E_{\mathrm{F}}^{\mathrm{w}}$, and ET takes place to reach a new equilibrium at the interface [8]. In the case of the AuNP nanofilm, the Fermi level of electrons in the nanofilm $\left(E_{\mathrm{F}}^{\mathrm{NP}}\right)$ adjusts so that both reactions (5) and (6) happen at the same rate. If back-reactions can be neglected, the steady-state $E_{\mathrm{F}}^{\mathrm{NP}}$ can be estimated as:

$E_{\mathrm{F}}^{\mathrm{NP}}=\frac{\left(\left(1-\alpha_{\mathrm{w}}\right) n_{\mathrm{w}} E_{F}^{\mathrm{w}}+\alpha_{\mathrm{o}} n_{\mathrm{o}} E_{F}^{\mathrm{o}}\right)}{\left(\left(1-\alpha_{\mathrm{w}}\right) n_{\mathrm{w}}+\alpha_{\mathrm{o}} n_{\mathrm{o}}\right)}-\frac{R T}{\left(\left(1-\alpha_{\mathrm{w}}\right) n_{\mathrm{w}}+\alpha_{\mathrm{o}} n_{\mathrm{o}}\right)} \ln \left[\frac{n_{\mathrm{w}} A_{\mathrm{w}} k_{\mathrm{w}}^{0} c_{\mathrm{A}_{\mathrm{w}}^{0}}^{\mathrm{s}}}{n_{\mathrm{o}} A_{\mathrm{o}} k_{\mathrm{o}}^{0} c_{\mathrm{D}_{\mathrm{o}}^{0}}^{\mathrm{s}}}\right]$

where $k^{0}$ is the potential independent rate constant, $A$ is the area available for the reaction (being either that of a single NP or of an "island" of electronically interacting NPs), $\alpha$ is the charge transfer coefficient (commonly close to 0.5$), c_{\mathrm{A}_{\mathrm{w}}^{0}}^{\mathrm{s}}$ is the concentration of $\mathrm{A}_{\mathrm{w}}^{0}$ at the surface of the AuNP nanofilm on the aqueous side of the interface and $c_{\mathrm{D}_{\mathrm{o}}^{0}}^{\mathrm{s}}$ is the concentration of $\mathrm{D}_{\mathrm{o}}^{0}$ at the surface of the AuNP nanofilm on the organic side of the interface. It is worth noting that the position of $E_{\mathrm{F}}^{\mathrm{NP}}$ is determined by the surface concentrations of the donor and acceptor species and not their bulk concentrations, as concentration polarization occurs. 


\subsection{Insights into the mechanism of biphasic $\mathrm{O}_{2}$ reduction on AuNP nanofilm modified soft interfaces in the presence of lipophilic electron donor redox couples by cyclic voltammetry.}

Cyclic voltammograms (CVs) of the relatively weak lipophilic electron donor Fc, with a standard redox potential in TFT vs. SHE $\left(\left[E_{\mathrm{Fc}^{+} / \mathrm{Fc}}^{0}\right]_{\mathrm{SHE}}^{\mathrm{TFT}}\right)$ of $+720 \mathrm{mV}[8]$, in the presence and absence of interfacial AuNP nanofilms formed with either 12 or $38 \mathrm{~nm}$ mean diameter AuNPs, at neutral $\mathrm{pH}$ and under either aerobic or anaerobic conditions are shown in Figure 2A-B.

Figure 2. Cyclic voltammograms (CVs) at bare and AuNP nanofilm modified soft interfaces allow the detection of the oxidised lipophilic electron donor species generated in the interfacial region, (A) and (B) $\mathrm{Fc}^{+}\left(\Delta_{\mathrm{o}}^{\mathrm{w}} \phi_{1 / 2}\left(\mathrm{Fc}^{+}\right)=+115 \mathrm{mV}\right)$ and (C) and (D) $\mathrm{DMFc}^{+}\left(\Delta_{\mathrm{o}}^{\mathrm{w}} \phi_{1 / 2}\left(\mathrm{DMFc}^{+}\right)=-\right.$ $258 \mathrm{mV}$ ), after charging of the interfacial AuNP films of 12 and $38 \mathrm{~nm}$ mean diameter AuNPs, respectively, by Fermi level equilibration under (A), (C) aerobic and (C), (D) anaerobic conditions. Secondly, CVs provide clear evidence of (C), (D) interfacial electron transfer between DMFc and aqueous $\mathrm{O}_{2}$ via the AuNP nanofilms due to the appearance of a significant current wave at $\Delta_{\mathrm{o}}^{\mathrm{w}} \phi=50 \mathrm{mV}$ under aerobic conditions only. The electrochemical cells used are described in Figure 1B, with a blank cell being a CV taken in the absence of an electron donor ( $x$ $=0$ ) at a bare soft interface. The scan rate was $25 \mathrm{mV} \mathrm{s}^{-1}$ in all cases. Also note in (D) $\Delta_{\mathrm{o}}^{\mathrm{w}} \phi_{1 / 2}\left(\mathrm{TPropA}^{+}\right)=-19 \mathrm{mV}$.

Blank CVs, without Fc or the AuNP nanofilm present, show that the polarisable potential window was limited by IT of $\mathrm{Li}^{+}$and $\mathrm{Cl}^{-}$at the positive and negative ends of the potential window, respectively. No detectable IT response for $\mathrm{Fc}^{+}$was observed within the potential window in the absence of the AuNP nanofilm, indicating that the IT-ET mechanism at neutral $\mathrm{pH}$ with Fc (equations (3) and (4)) is kinetically limited [8]. Nonetheless, on functionalization of the interface with a AuNP nanofilm, a significant IT response was observed at the characteristic half-wave IT potential of $\mathrm{Fc}^{+}$at the water|TFT interface $\left(\Delta_{\mathrm{o}}^{\mathrm{w}} \phi_{1 / 2}\left(\mathrm{Fc}^{+}\right)=+115 \pm 5 \mathrm{mV}\right)$. The latter wave was also observed under anaerobic conditions (Figure 2B) indicating that interfacial $\mathrm{Fc}^{+}$ was predominantly generated by charging of the AuNP nanofilm (equation (5)). 
Next, we considered biphasic $\mathrm{O}_{2}$ reduction by a stronger electron donor, DMFc $\left(\left[E_{\mathrm{DMFc}^{+} / \mathrm{DMFc}}^{0}\right]_{\mathrm{SHE}}^{\mathrm{TFT}}=+80 \mathrm{mV}\right)$ in Figure 2C. Unlike Fc, solutions of DMFc always contain some oxidised $\mathrm{DMFc}^{+}$species leading to an IT response at $\Delta_{\mathrm{o}}^{\mathrm{w}} \phi_{1 / 2}\left(\mathrm{DMFc}^{+}\right)=-258 \pm 5 \mathrm{mV}$. The peak current after the reversal of the sweep direction at the positive end of the potential window is smaller in comparison with the situation for a blank cell (Figure 2C). Additionally, the magnitude of the $\mathrm{DMFc}^{+}$IT response diminishes considerably under anaerobic conditions (Figure 2D), indicating that most of the $\mathrm{DMFc}^{+}$was generated during biphasic $\mathrm{O}_{2}$ reduction as detailed in equations (3) and (4). On functionalization of the interface with a AuNP nanofilm under aerobic conditions, the magnitude of the $\mathrm{DMFc}^{+}$IT response increased dramatically and an irreversible wave with an onset $\Delta_{\mathrm{o}}^{\mathrm{w}} \phi$ of approximately $+50 \mathrm{mV}$ was observed (Figure $2 \mathrm{C}$ ). The role of $\mathrm{O}_{2}$ was further clarified as, under anaerobic conditions, in the presence of an AuNP nanofilm, the enlarged $\mathrm{DMFc}^{+}$IT response remained but the irreversible wave disappeared, with the potential window once more limited by the $\mathrm{IT}_{\mathrm{T}} \mathrm{Li}^{+}$at positive potentials (Figure 2D). Thus, in the absence of $\mathrm{O}_{2}, \mathrm{DMFc}^{+}$was generated predominately by charging of the AuNP nanofilm (equation (5)), similar to the case of Fc.

IET from lipophilic DMFc to aqueous solubilised $\mathrm{O}_{2}$ is responsible for the irreversible voltammetric wave at $+50 \mathrm{mV}$, i.e., the positive current is due to the flow of negative charge (electrons) from the organic to aqueous phase via the conducting AuNP nanofilm. Crucially, the observation of this wave at an applied $\Delta_{\mathrm{o}}^{\mathrm{w}} \phi$ significantly below that required for IT of hydrated $\mathrm{Li}^{+}$(a key step in the biphasic reduction of organic solubilised $\mathrm{O}_{2}$ [17]) is clear evidence that, under the experimental conditions described herein, aqueous solubilised $\mathrm{O}_{2}$ is indeed being reduced (discussed more below). The reaction took place much faster with the AuNP nanofilm present (tens of minutes) than is the case for the $\mathrm{Li}^{+}$IT induced mechanism (equations (3) and (4)), which occurs on the time-scale of hours. Hence, the AuNP nanofilm acts as an interfacial redox catalyst. The charging of the AuNP nanofilm by Fermi level equilibration is discussed in further detail vide infra.

The magnitude of the IT responses for $\mathrm{DMFc}^{+}$were greater for the $38 \mathrm{~nm}$ AuNP film probably due to the more oxidised state of the $38 \mathrm{~nm}$ AuNPs in comparison with the $12 \mathrm{~nm}$ ones (in other words, the $38 \mathrm{~nm}$ AuNPs required more electron donor molecules to reach the same Fermi-level as the $12 \mathrm{~nm}$ ones). Additionally, larger particles have higher capacitance and hence more charge is required to shift the Fermi level of electrons in the nanofilm [34].

Finally, let us consider other possible routes leading to $\mathrm{O}_{2}$ reduction in the biphasic system. Thermodynamically the homogenous reduction of $\mathrm{O}_{2}$ to $\mathrm{H}_{2} \mathrm{O}_{2}$ or $\mathrm{H}_{2} \mathrm{O}$ by $\mathrm{Fc}$ or DMFc in 
TFT is feasible. The redox potentials in TFT can be estimated if the Gibbs energy of transfer of protons and $\mathrm{H}_{2} \mathrm{O}$ are known, as described previously $[12,42] . \Delta G_{\mathrm{tr}, \mathrm{H}^{+}}^{0, \mathrm{TFT}}$ was estimated as 69 $\mathrm{kJ} \mathrm{mol}^{-1}$ from the linear relationship of the standard IT energies between TFT and DCE in Appendix A (note that the standard IT transfer energies for TFT were recalculated from data presented in reference [10], utilising a viscosity of $0.527 \mathrm{mPa}$ instead of $0.038 \mathrm{mPa}$ s for TFT, and taking $\Delta G_{\text {tr, } \mathrm{H}^{+}}^{0, \mathrm{DCE}}$ as $53 \mathrm{~kJ} \mathrm{~mol}^{-1}$ ), and $\Delta G_{\mathrm{tr}, \mathrm{H}_{2} \mathrm{O}}^{0, \mathrm{w} \rightarrow \mathrm{TFT}}$ was estimated as $15.2 \mathrm{~kJ} \mathrm{~mol}^{-1}$ from liquid-liquid equilibrium data between TFT, water and isopropanol from reference [46] assuming no excess molar volumes and utilising the lowest isopropanol concentration. The final results are $\left[E_{\mathrm{O}_{2} / \mathrm{H}_{2} \mathrm{O}_{2}}^{0}\right]_{\mathrm{SHE}}^{\mathrm{TFT}}=1.36 \mathrm{~V}$ and $\left[E_{\mathrm{O}_{2} / \mathrm{H}_{2} \mathrm{O}}^{0}\right]_{\mathrm{SHE}}^{\mathrm{TFT}}=1.91 \mathrm{~V}$, respectively (see Appendices $\mathrm{A}$ and $\mathrm{B}$ for further details). Additionally, the solubility of $\mathrm{O}_{2}$ in water is only $0.27 \mathrm{mM}$, while the values in DCE and chlorobenzene are 1.38 and $1.62 \mathrm{mM}[47,48]$, respectively. Thus, the solubility of $\mathrm{O}_{2}$ is 5 to 7 times higher in the organic phase. However, homogenous reduction of $\mathrm{O}_{2}$ by $\mathrm{DMFc}$ (and by extrapolation Fc) in TFT catalysed by the AuNP nanofilm is unlikely as, noted earlier, the onset potential of the catalytic wave associated with $\mathrm{O}_{2}$ reduction occurs at applied potentials below those required to pump $\mathrm{Li}^{+}$, and the associated hydration shell, across the interface (equation (3)). This is key as the catalytic wave appears at applied potentials where protons cannot be present in the organic phase, a significant departure from the scenario detailed previously in reference [17] and in equations (3) and (4). In the latter case we believe that the mechanism of $\mathrm{O}_{2}$ reduction proceeds by DMFc-hydride formation, followed by proton coupled electron transfer (PCET) to $\mathrm{O}_{2}$ to give the $\mathrm{HO}_{2}{ }^{\bullet}$ radical. From there the reaction can proceed either by ET to give $\mathrm{HO}_{2}{ }^{-}$followed by proton transfer from acid, or PCET to give $\mathrm{H}_{2} \mathrm{O}_{2}$ directly [17]. However, herein, in the absence of protons in the organic phase, the DMFc-hydride is not formed and DMFc simply acts as an electron donor. Thus, as detailed by Koper, the first step of the mechanism under these conditions in the presence of gold is considered to be ET (from DMFc in our case) to $\mathrm{O}_{2}$ forming the superoxide at the surface of the gold substrate [49-51]. However, the production of superoxide in the organic phase is very difficult from a thermodynamic point of view: the standard redox potential for $\mathrm{O}_{2}^{-}$in water is $-0.330 \mathrm{~V} v \mathrm{~s}$. SHE, whereas the value in DCE, for example, becomes $-0.81 \mathrm{~V} v s$. SHE, as calculated by Su [9]. The latter value should be of the same order in TFT. Therefore, the aqueous ORR is more likely via direct IET from the organic electron donor to aqueous $\mathrm{O}_{2}$. Furthermore, as the reaction of organic solubilised $\mathrm{O}_{2}$ with DMFc catalysed by the AuNP nanofilm would be homogeneous, the Galvani potential difference would not play a role in the homogeneous redox catalysis of superoxide generation. 
Scheme 1. Representation of the mechanism of $\mathrm{O}_{2}$ reduction in the aqueous phase at a AuNP nanofilm modified soft interface. AuNPs were charged by an electron donor (DMFc) in the organic phase that acts as a barrier-free shortcut for electrons to the aqueous phase.

\subsection{Comparison of cyclic voltammograms obtained at ITIES and physically separated oil- water phases connected by gold electrodes}

In order to confirm that the obtained increase of current was due to electron transfer with subsequent $\mathrm{O}_{2}$ reduction in the aqueous phase, an experiment with two phases separated but electrically connected with gold electrodes was carried out. Comparison of CVs for physically separated oil-water phases with those recorded at an ITIES supported 38nm AuNP nanofilm are presented in Figure 3.

Figure 3. Comparison of CVs ( $i R$ compensated) recorded at an ITIES separated by a nanofilm of $38 \mathrm{~nm}$ AuNPs and physically separated oil-water phases electrically connected with $3 \mathrm{~mm}$ in diameter gold electrodes. Scan rate is $50 \mathrm{mV} \mathrm{s}^{-1}$ in all cases.

Experiments done with the electric conductor separated oil-water system show an irreversible wave with an onset potential of +50 to $+100 \mathrm{mV}$. As this wave can only result from direct electron transfer from the organic phase into the aqueous phase, this experiment confirms that IET from lipophilic DMFc to aqueous $\mathrm{O}_{2}$ is responsible for the irreversible voltammetric wave at $+50 \mathrm{mV}$ also observed in the four-electrode cell. The latter confirms the assumption that $\mathrm{O}_{2}$ reduction occurs in the aqueous phase as depicted in Scheme 1. This assumption is also in line with the work of Dryfe and co-workers who demonstrated in-depth that biphasic $\mathrm{O}_{2}$ reduction could be driven between two physically separated solutions, an acidic aqueous phase and an organic phase containing a lipophilic electron donor, that were electrically connected by a thermally annealed gold wire [13]. Thus, their system also expressly precluded the possibility of IT in the mechanism and highlighted the feasibility of $\mathrm{O}_{2}$ reduction on the aqueous side of an adsorbed interfacial AuNP nanofilm. 


\subsection{Effect of $\mathrm{pH}$ on biphasic $\mathrm{O}_{2}$ reduction at AuNP nanofilm modified soft interfaces in the presence of a lipophilic electron donor redox couple}

Reduction of $\mathrm{O}_{2}$ at the surface of a gold electrode is known to be strongly dependent on the $\mathrm{pH}$ of the medium $[49,50,52]$. The catalytic activity of gold towards the ORR is higher in alkaline rather than acidic media as under these conditions the rate-determining step (formation of the superoxide anion by outer sphere electron transfer) does not depend on $\mathrm{pH}$ and overpotentials towards $2 e^{-}$and $4 e^{-}$reductions are lower [49]. Also, the $d$-band of gold was shown to not be involved in the catalytic process in a basic environment. The latter leads to the formation of weakly bound intermediates, thus increasing the catalytic activity of gold in comparison to acidic conditions. However, this behaviour is usually a sign of decoupled protonelectron transfer step in the mechanism [52].

A series of experiments in acidic and alkaline conditions were carried out in order to reveal the effect of $\mathrm{pH}$ on $\mathrm{O}_{2}$ reduction at AuNP nanofilm modified soft interfaces. As expected, $\mathrm{pH}$ has a major effect on the cyclic voltammograms presented in Figure 4.

Figure 4. Cyclic voltammograms (CVs) at AuNP $(38 \mathrm{~nm})$ nanofilm modified soft interfaces showing the strong effect of $\mathrm{pH}$ on the onset potential of the irreversible electrocatalytic wave. The concentration of DMFc in TFT was set to $0.5 \mathrm{mM}$. The scan rate was $75 \mathrm{mV} \mathrm{s}^{-1}$ in all cases.

In acidic conditions ( $\mathrm{pH} \sim 3$ ) the onset potential of the electrocatalytic wave was shifted left, to more negative potentials, by $c a .120 \mathrm{mV}$ in comparison with neutral conditions. Meanwhile, in an alkaline environment the onset potential was shifted right, to more positive potentials, by $c a .90 \mathrm{mV}$. If the electrocatalytic performance of the gold film did not depend on $\mathrm{pH}$, the expected shift would be $c a .60 \mathrm{mV}$ per $\mathrm{pH}$ unit, so, from a thermodynamic point of view, the shift of the onset potential in acidic conditions should have been $240 \mathrm{mV}$ instead of $120 \mathrm{mV}$. This is because the kinetics of oxygen reduction is slower on gold in acidic conditions, so the increased thermodynamic driving force is compensated with additional overpotential required to drive the reaction. The same applies to alkaline conditions. The thermodynamic driving force for the reaction decreases by $240 \mathrm{mV}$, but the onset potential decreases by only $90 \mathrm{mV}$, because less over potential is required for oxygen reduction in alkaline conditions on gold. 


\subsection{Quantification of $\mathrm{H}_{2} \mathrm{O}_{2}$ formation by the biphasic $\mathrm{O}_{2}$ reduction under neutral conditions at AuNP nanofilm modified soft interfaces in the presence of a lipophilic electron donor redox couple.}

The yield of $\mathrm{H}_{2} \mathrm{O}_{2}$ for the shake-flask outlined in Figure 1C with DMFc was ca. 22\% (see reference [18] for a detailed description of this methodology) verifying that kinetically rapid biphasic $\mathrm{O}_{2}$ reduction occurred in the presence of a AuNP nanofilm. This value represents the ratio of the detected $\mathrm{H}_{2} \mathrm{O}_{2}$ concentration $(0.10 \mathrm{mM}$; from the iodide titration method, see inset Figure 5) to the theoretical $\mathrm{H}_{2} \mathrm{O}_{2}$ concentration $(0.45 \mathrm{mM}$; calculated stoichiometrically from the concentration of $\mathrm{DMFc}^{+}$of $0.9 \mathrm{mM}$ detected post-reaction by UV/vis spectroscopy, see Figure 5). The detection of $\mathrm{H}_{2} \mathrm{O}_{2}$ well below the theoretical maximum concentration indicates that biphasic $\mathrm{O}_{2}$ reduction proceeds by both the $2 e^{-}$and $4 e^{-}$reduction pathways generating $\mathrm{H}_{2} \mathrm{O}_{2}$ and $\mathrm{H}_{2} \mathrm{O}$, respectively, or more likely, by (i) direct reduction of $\mathrm{H}_{2} \mathrm{O}_{2}$ to $\mathrm{H}_{2} \mathrm{O}$ in the $2+2$ electron mechanism $[11,12,53]$ and/or (ii) disproportionation of two $\mathrm{H}_{2} \mathrm{O}_{2}$ molecules to $\mathrm{H}_{2} \mathrm{O}$ and $\mathrm{O}_{2}[11,12]$.

Figure 5. Identification of the presence, and determination of the yields, of the biphasic $\mathrm{O}_{2}$ reduction reaction products, $\mathrm{DMFc}^{+}$and $\mathrm{H}_{2} \mathrm{O}_{2}$. Main graph: $\mathrm{UV} / \mathrm{vis}$ spectra of an organic solution of $4 \mathrm{mM} \mathrm{DMFc}$ in TFT before $(\mathrm{t}=0$ minutes $)$ and post-reaction for the shake-flask reaction outlined in Figure $1 \mathrm{C}$. The oxidation product of the biphasic $\mathrm{O}_{2}$ reduction reaction, $\mathrm{DMFc}^{+}$was quantified from the magnitude of its absorption peak using the Beer-Lambert Law; $\lambda_{\max }$ for $\mathrm{DMFc}^{+}$is $779 \mathrm{~nm}$ and the extinction coefficient of $\mathrm{DMFc}^{+}$in a similar organic phase, 1,2-dichloroethane, is $0.632 \mathrm{mM}^{-1} \mathrm{~cm}^{-1}$ [21]. Inset: Characteristic UV/vis spectra of the two distinguishing absorption peaks of the $\mathrm{I}_{3}{ }^{-}$cation in the aqueous phase diluted by half $\left(\lambda_{\max }=288\right.$ and $354 \mathrm{~nm}$ ) formed after interaction of the $\mathrm{H}_{2} \mathrm{O}_{2}$ generated during the biphasic $\mathrm{O}_{2}$ reduction reaction with an excess of KI over 30 minutes [18].

\subsection{Mechanism of biphasic $\mathrm{O}_{2}$ reduction by interfacial redox catalysis under neutral conditions at AuNP nanofilm modified soft interfaces.}

Herein, two different redox couples are present in separate immiscible phases, $\mathrm{O}_{2} / \mathrm{H}_{2} \mathrm{O}_{2}$ in the aqueous phase and $\mathrm{DMFc}^{+} / \mathrm{DMFc}$ in the organic phase. At equilibrium, the Fermi levels of the electrons in both phases are aligned but thermodynamic equilibrium may not be reached due to kinetic limitations. Adsorption of a nanofilm of metallic AuNPs has two key effects: (i) acting 
as a conductor (or a bipolar electrode due to relatively large diameter of the AuNPs, $12 \mathrm{~nm}$ and $38 \mathrm{~nm}$, respectively, in comparison to the interfacial region, $\sim 1-2 \mathrm{~nm}$ ) facilitating IET across the soft interface and (ii) providing a catalytic surface to significantly enhance the rate of reaction for the reduction of aqueous solubilised $\mathrm{O}_{2}$. Thus, the AuNP film facilitates Fermi level equilibration between the lipophilic donor, $\mathrm{DMFc}^{+/ 0}$, and an acceptor, $\mathrm{O}_{2} / \mathrm{H}_{2} \mathrm{O}_{2}$ or $\mathrm{O}_{2} / \mathrm{H}_{2} \mathrm{O}$ redox couples (Scheme 2), overcoming the kinetic limitations at bare soft interfaces and thereby achieving interfacial redox catalysis.

Scheme 2. Interfacial redox catalysis: equilibration of the Fermi level of the electrons in a AuNP nanofilm $\left(E_{\mathrm{F}}^{\mathrm{NP}}\right)$ adsorbed at a soft interface with those of two redox couples in solution, one in the aqueous phase and the other in the organic phase. The AuNP is charged during this process by the electron donors, Fc or DMFc, such that it acts as an "interfacial reservoir of electrons", and the final position of $E_{\mathrm{F}}^{\mathrm{NP}}$ (a turquoise line for $\Delta_{\mathrm{o}}^{\mathrm{w}} \phi=0 \mathrm{~V}$ and a red line for $\Delta_{\mathrm{o}}^{\mathrm{w}} \phi=0.1 \mathrm{~V}$, respectively) is determined by the kinetics of both the oxidation half-reaction on the organic side of the interfacial AuNP nanofilm (equation (10)) and the reduction half-reaction on the aqueous side (equations (11) and (12)) [8]. Interfacial electron transfer (IET) between the two redox couples via the conductive AuNP and the provision of a catalytic surface to facilitate $\mathrm{O}_{2}$ reduction both combine to significantly enhance the kinetics of the otherwise sluggish biphasic $\mathrm{O}_{2}$ reduction reaction (ORR). The standard redox potentials of all redox couples are expressed versus both the Standard Hydrogen Electrode (SHE) and Absolute Vacuum Scale (AVS), respectively. The values for oxygen reduction reactions are expressed at $\mathrm{pH} 7$, in air, and for unity of activity for $\mathrm{H}_{2} \mathrm{O}_{2}$ The black and red dotted lines show the shift of the Fermi levels of electrons in redox couples dissolved in the organic phase in relation to aqueous redox couples, when $\Delta_{\mathrm{o}}^{\mathrm{w}} \phi=0 \mathrm{~V}$ and $0.1 \mathrm{~V}$, respectively.

Initially, $E_{\mathrm{F}}^{\mathrm{NP}}$ is lower than the Fermi level of electrons in the $\mathrm{Fc}^{+/ 0}$ couple, as evident from the increased interfacial concentration of $\mathrm{Fc}^{+}$(detected by $\mathrm{CV}$ at the soft interface, Figure 2A) after ET from Fc to the AuNP nanofilm under either aerobic or anaerobic conditions. The initial low $E_{\mathrm{F}}^{\mathrm{NP}}$ may be due to Fermi level equilibration between the AuNPs and $\mathrm{O}_{2}$ $\left(\left[E_{\mathrm{O}_{2} / \mathrm{H}_{2} \mathrm{O}}\right]_{\mathrm{SHE}}^{\mathrm{w}, \mathrm{pH} 7 \text {, in air }}=+805 \mathrm{mV}\right)$ post-synthesis. The charge on the interfacial AuNP nanofilm, under either aerobic or anaerobic conditions, was immediately imposed by the $\mathrm{DMFc}^{+/ 0}$ redox couple on contact due to an electrostatic charging process (Scheme 2): 
$n \mathrm{DMFc}_{\mathrm{o}}+\mathrm{AuNP}_{\mathrm{int}}^{z} \rightleftarrows n \mathrm{DMFc}_{\mathrm{o}}^{+}+\mathrm{AuNP}_{\mathrm{int}}^{z-n}$

It should be emphasised that $E_{F}^{\mathrm{o}}$, and therefore the position of $E_{\mathrm{F}}^{\mathrm{NP}}$, may lie at more negative (reducing) potentials than $\left[E_{\mathrm{D}_{\mathrm{o}}^{+} \mathrm{D}_{\mathrm{o}}}^{0}\right]_{\mathrm{SHE}}^{\mathrm{o}}$ (as shown for the $\mathrm{DMFc}^{+/ 0}$ redox couple in Scheme 2 even when $\left.\Delta_{\mathrm{o}}^{\mathrm{w}} \phi=0 \mathrm{~V}\right)$. This is because the redox potential of the $\mathrm{D}_{\mathrm{o}}^{+} / \mathrm{D}_{\mathrm{o}}$ couple at the AuNP surface is determined by the Nernst equation and therefore relies explicitly on the ratio of the surface concentrations of $\mathrm{D}_{0}^{+}$and $\mathrm{D}_{\mathrm{o}}$. As initially only DMFc is present and no oxygen reduction takes place, the Fermi level of the NP increases above the standard redox potential.

Subsequently, the charged AuNP nanofilm was capable of reducing aqueous $\mathrm{O}_{2}$ under neutral conditions with some driving force $\left(\Delta_{\mathrm{o}}^{\mathrm{w}} \phi=+50 \mathrm{mV}\right)$ provided by polarisation of the soft interface:

$$
\begin{aligned}
& \mathrm{AuNP}_{\mathrm{int}}^{z{ }^{n}}+\mathrm{O}_{2, \mathrm{w}}+2 \mathrm{H}_{\mathrm{w}}^{+} \rightarrow \mathrm{AuNP}_{\mathrm{int}}^{z n+2}+2 \mathrm{H}_{2} \mathrm{O}_{2, \mathrm{w}} \\
& \mathrm{AuNP}_{\mathrm{int}}^{z-n}+\mathrm{O}_{2, \mathrm{w}}+4 \mathrm{H}_{\mathrm{w}}^{+} \rightarrow \mathrm{AuNP}_{\mathrm{int}}^{z-n+4}+2 \mathrm{H}_{2} \mathrm{O}_{\mathrm{w}}
\end{aligned}
$$

Additionally, any $\mathrm{H}_{2} \mathrm{O}_{2}$ generated can be further reduced to $\mathrm{H}_{2} \mathrm{O}$ or disproportionate:

$$
\begin{aligned}
& \mathrm{AuNP} \mathrm{int}^{z-n}+\mathrm{H}_{2} \mathrm{O}_{2, \mathrm{w}}+2 \mathrm{H}_{\mathrm{w}}^{+} \rightarrow \mathrm{AuNP}_{\mathrm{int}}^{z-n+2}+2 \mathrm{H}_{2} \mathrm{O}_{\mathrm{w}} \\
& 2 \mathrm{H}_{2} \mathrm{O}_{2, \mathrm{w}} \rightarrow \mathrm{O}_{2, \mathrm{w}}+2 \mathrm{H}_{2} \mathrm{O}_{\mathrm{w}}
\end{aligned}
$$

Theoretically, the equilibrium Galvani potential difference required to drive biphasic $\mathrm{O}_{2}$ reduction can be calculated from equations (15) and (16) [8]:

$$
\begin{aligned}
& \Delta_{\mathrm{O}}^{\mathrm{w}} \phi_{\mathrm{eq}}=\left[E_{\mathrm{D}^{+} / \mathrm{D}}\right]_{\mathrm{SHE}}^{\mathrm{O}}-\left[E_{\mathrm{O}_{2} / \mathrm{H}_{2} \mathrm{O}}\right]_{\mathrm{SHE}}^{\mathrm{w}} \\
& {\left[E_{\mathrm{O}_{2} / \mathrm{H}_{2} \mathrm{O}}\right]_{\mathrm{SHE}}^{\mathrm{w}}=\left[E_{\mathrm{O}_{2} / \mathrm{H}_{2} \mathrm{O}}^{0}\right]_{\mathrm{SHE}}^{\mathrm{w}}+\frac{R T}{4 F} \ln \left(\frac{f_{\mathrm{O}_{2}}}{p^{0}}\right)+\frac{R T}{F} \ln \left(a_{\mathrm{H}^{+}}\right)}
\end{aligned}
$$

In this case the $\mathrm{pH}$ of the solution is 7 and the fugacity of $\mathrm{O}_{2}$ can be taken as the partial pressure of $\mathrm{O}_{2}$ in air, giving a final value of $\left[E_{\mathrm{O}_{2} / \mathrm{H}_{2} \mathrm{O}}\right]_{\mathrm{SHE}}^{\mathrm{w}, \mathrm{pH} 7 \text {, in air }}=+804 \mathrm{mV}$. For $\mathrm{O}_{2}$ reduction to $\mathrm{H}_{2} \mathrm{O}_{2}$ the final value of $\left[E_{\mathrm{O}_{2} / \mathrm{H}_{2} \mathrm{O}_{2}}\right]_{\mathrm{SHE}}^{\mathrm{w}, \mathrm{pH} 7 \text {, in air }}=+261 \mathrm{mV}$, considering activity of unity for $\mathrm{H}_{2} \mathrm{O}_{2}$ and $T=298 \mathrm{~K}$ ) If we consider the onset potential as the potential where $1 \%$ of DMFc has been oxidized, then $\left[E_{\mathrm{DMFc}^{+} / \mathrm{DMFc}}\right]_{\mathrm{SHE}}^{\mathrm{TFT}}=-38 \mathrm{mV}$, so we should see the onset of $\mathrm{O}_{2}$ reduction to $\mathrm{H}_{2} \mathrm{O}$ at $\Delta_{\mathrm{O}}^{\mathrm{w}} \phi=-724 \mathrm{mV}$ and to $\mathrm{H}_{2} \mathrm{O}_{2}$ at $\Delta_{\mathrm{O}}^{\mathrm{w}} \phi=-337 \mathrm{mV}$ (considering the Nernst potential for an aqueous solution of $5 \mu \mathrm{M}$ of $\mathrm{H}_{2} \mathrm{O}_{2}$ or $2.5 \mu \mathrm{M}$ of $\mathrm{H}_{2} \mathrm{O}$ and $10 \mu \mathrm{M} \mathrm{OH}^{-}$produced by oxidation 
of $10 \mu \mathrm{M}$ of DMFc, as calculated in Appendix C). Hence, the required overpotential for the reactions are $774 \mathrm{mV}$ for the $4 e^{-}$reduction pathway and $387 \mathrm{mV}$ for the $2 e^{-}$reduction pathway, respectively, as $\Delta_{\mathrm{o}}^{\mathrm{w}} \phi=+50 \mathrm{mV}$ is required for the onset of reaction. The latter indicates that further scope to improve the efficiency of biphasic $\mathrm{O}_{2}$ reduction remains. However, these overpotential values are comparable to typical onset potentials of $\mathrm{O}_{2}$ reduction on gold electrodes [50].

Additionally, as the overpotential for $\mathrm{O}_{2}$ reduction at the surface of a AuNP nanofilm is identical for experiments involving either DMFc or Fc, any current wave due to IET for an electrochemical cell containing Fc lies outside the polarisable potential window at $+690 \mathrm{mV}$. Thus, the wave at the edge of the polarisable potential window for an electrochemical cell containing Fc and the AuNP film (Figure 1A) could be either due to slight catalysis of the homogeneous ET step in the IT-ET mechanism (an unlikely possibility as discussed vide supra) or slight catalysis of IET from $\mathrm{Fc}$ to aqueous $\mathrm{O}_{2}$.

As discussed in section 3.3, the rate-limiting step of the ORR on gold is considered to be the irreversible formation of the superoxide (equation (17)), followed by fast formation of $\mathrm{H}_{2} \mathrm{O}_{2}$ (equation (18)), while the AuNP nanofilm is charged by oxidation of DMFc (equation (19)):

$\mathrm{O}_{2, \mathrm{w}}+\mathrm{e}^{-} \rightarrow \mathrm{O}_{2, \mathrm{w}}^{-}$

$\mathrm{O}_{2, \mathrm{w}}^{-}+2 \mathrm{H}_{\mathrm{w}}^{+}+\mathrm{e}^{-} \rightarrow \mathrm{H}_{2} \mathrm{O}_{2, \mathrm{w}}$

$\mathrm{DMFc}_{\mathrm{o}} \rightleftarrows \mathrm{DMFc}_{\mathrm{o}}^{+}+\mathrm{e}^{-}$

For simplicity, $\mathrm{O}_{2}$ reduction is considered as one reaction to give $\mathrm{H}_{2} \mathrm{O}_{2}$. If we assume that $\alpha_{\mathrm{w}}=\alpha_{\mathrm{o}}=0.5$, and because the total number of electrons in the aqueous and organic reactions are $n_{\mathrm{w}}=2$ and $n_{\mathrm{o}}=1, E_{\mathrm{F}}^{\mathrm{NP}}$ can be estimated from equation (9). In addition, the active area available for electrochemical reactions can be considered as the projected area available for diffusion. This area is roughly equal on both sides of the interface (most likely, particles are split equally by the interface due to stability reasons $[1,54,55])$, so $A_{\mathrm{w}} / A_{\mathrm{o}}$ was chosen equal to unity. As the bulk concentrations of both DMFc and $\mathrm{O}_{2}$ are of similar magnitude, and considering that $\mathrm{O}_{2}$ is present in both phases and at least two DMFc molecules are needed for each reacted $\mathrm{O}_{2}$ molecule, the surface concentration ratio $c_{\mathrm{O}_{2 . \mathrm{w}}}^{\mathrm{s}} / c_{\mathrm{DMFc}_{\mathrm{o}}}^{\mathrm{s}} \approx 1$. Herein, $\mathrm{O}_{2}$ reduction on the AuNP nanofilm (equations (11) and (12)) is a relatively sluggish process [50] in comparison to charging of the AuNP nanofilm with $\mathrm{DMFc}^{+/ 0}$ (equation (10)), a very facile outer-sphere one-electron reaction. Thus, we can consider that $k_{\mathrm{w}}^{0} / k_{\mathrm{o}}^{0} \approx 1 \times 10^{-5}$, and equation (9) becomes: 


$$
E_{\mathrm{F}}^{\mathrm{NP}} \approx \frac{2\left(E_{\mathrm{F}}^{\mathrm{w}}+E_{\mathrm{F}}^{\mathrm{o}} / 2\right)}{3}-\frac{2 R T}{3} \ln \left(2 \times 10^{-5}\right)
$$

Equation (20) indicates that $E_{\mathrm{F}}^{\mathrm{NP}}$ is close to the Fermi level of the electrons in the $\mathrm{DMFc}^{+/ 0}$ redox couple (i.e. $\left.E_{\mathrm{F}}^{\mathrm{o}}\right)$. Indeed, $E_{\mathrm{F}}^{\mathrm{NP}}$ was raised to the extent that the AuNPs acted as an "interfacial reservoir of electrons".

We can substitute the expressions for the Fermi levels of the electrons of the redox couples at the AuNP surface in the aqueous phase $\left(\mathrm{O}_{2}\right.$ reduction, see equation (17)) and organic phase (DMFc oxidation, see equation (19)), respectively, into equations (7) and (8) to get:

$$
E_{\mathrm{F}}^{\mathrm{w}}=-F\left[\left[E_{\mathrm{O}_{2} / \mathrm{H}_{2} \mathrm{O}_{2}}^{0}\right]_{\mathrm{SHE}}^{\mathrm{w}}+\frac{R T}{2 F} \ln \left(\frac{f^{\mathrm{s}} \mathrm{O}_{2}}{p^{0}}\right)+\frac{R T}{F} \ln \left(a_{\mathrm{H}^{+}}^{\mathrm{s}}\right)-\frac{R T}{2 F} \ln \left(a_{\mathrm{H}_{2} \mathrm{O}_{2}}^{\mathrm{s}}\right)+\phi_{\mathrm{w}}+\left[E_{\mathrm{H}^{+} / 1 / 2 \mathrm{H}_{2}}^{0}\right]_{\mathrm{AVS}}^{\mathrm{w}}\right]
$$

$$
E_{F}^{\mathrm{o}}=-F\left[\left[E_{\mathrm{DMFc}_{\mathrm{o}}^{+} / \mathrm{DMFc}_{\mathrm{o}}}^{0}\right]_{\mathrm{SHE}}^{\mathrm{o}}+\frac{R T}{F} \ln \left(\frac{a_{\mathrm{DMF}_{\mathrm{o}}^{+}}^{s}}{a_{\mathrm{DMF}_{\mathrm{o}}^{0}}^{s}}\right)+\phi_{\mathrm{o}}+\left[E_{\mathrm{H}^{+} / 1 / 2 \mathrm{H}_{2}}^{0}\right]_{\mathrm{AVS}}^{\mathrm{w}}\right]
$$

The driving forces for $\mathrm{O}_{2}$ reduction and DMFc oxidation are:

$$
\begin{aligned}
& E_{\mathrm{F}}^{\mathrm{NP}}-E_{\mathrm{F}}^{\mathrm{w}} \approx \frac{F}{3}\left(\left[E_{\mathrm{O}_{2, \mathrm{w}} / \mathrm{H}_{2} \mathrm{O}_{2, \mathrm{w}}}\right]_{\mathrm{AVS}}^{\mathrm{w}}-\left[E_{\mathrm{DMFc}_{\mathrm{o}}^{+} / \mathrm{DMFc}_{\mathrm{o}}}\right]_{\mathrm{AVS}}^{\mathrm{o}}\right)+\frac{F\left(\phi_{\mathrm{w}}-\phi_{\mathrm{o}}\right)}{3}-\frac{2 R T}{3} \ln \left(2 \times 10^{-5}\right) \\
& E_{\mathrm{F}}^{\mathrm{o}}-E_{\mathrm{F}}^{\mathrm{NP}} \approx \frac{2 F}{3}\left(\left[E_{\mathrm{O}_{2} / \mathrm{H}_{2} \mathrm{O}_{2}}\right]_{\mathrm{AVS}}^{\mathrm{w}}-\left[E_{\mathrm{DMFc}^{+} / \mathrm{DMFc}}\right]_{\mathrm{AVS}}^{\mathrm{o}}\right)+\frac{2 F}{3}\left(\phi_{\mathrm{w}}-\phi_{\mathrm{o}}\right)+\frac{2 R T}{3} \ln \left(2 \times 10^{-5}\right)
\end{aligned}
$$

For example, now the current for $\mathrm{O}_{2}$ reduction can be expressed as:

$$
\begin{aligned}
& i_{\mathrm{w}}=-2 A_{\mathrm{w}} F k_{\mathrm{w}}^{0} c_{\mathrm{O}_{2}, \mathrm{w}}^{\mathrm{w}, \mathrm{s}} e^{2\left(1-\alpha_{\mathrm{w}}\right)\left(E_{\mathrm{F}}^{\mathrm{NP}}-E_{\mathrm{F}}^{\mathrm{w}}\right) / R T}= \\
& -2 A_{\mathrm{w}} F k_{\mathrm{w}}^{0} c_{\mathrm{O}_{2}, \mathrm{w}}^{\mathrm{w}, \mathrm{s}} e^{2\left(1-\alpha_{\mathrm{w}}\right)}\left(\frac { F } { 3 } \left(\left[E_{\mathrm{O}_{2, \mathrm{w}} / \mathrm{H}_{2} \mathrm{O}_{2, \mathrm{w}}}\right]_{\mathrm{AVS}}^{\mathrm{w}}-\left[E_{\left.\left.\left.\mathrm{DMFc}_{\mathrm{o}}^{+} / \mathrm{DMFc}_{\mathrm{o}}\right]_{\mathrm{AVS}}^{\mathrm{o}}\right)+\frac{F\left(\phi_{\mathrm{w}}-\phi_{\mathrm{o}}\right)}{3}-b\right) / R T}\right.\right.\right. \\
& \text { where } b=\frac{2 R T}{3} \ln \left[\frac{2 A_{\mathrm{w}} k_{\mathrm{w}}^{0} c_{\mathrm{O}_{2 . \mathrm{w}}}^{\mathrm{s}}}{A_{\mathrm{o}} k_{\mathrm{o}}^{0} c_{\mathrm{DMFc}_{\mathrm{o}}}^{\mathrm{s}}}\right]
\end{aligned}
$$

These equations show that the driving forces for both $\mathrm{O}_{2}$ reduction and DMFc oxidation depend on the Galvani potential difference. As $\mathrm{O}_{2}$ reduction and DMFc oxidation take place with the same current, and bulk concentrations are similar, surface concentration ratios of both redox species in equations (21) and (22) are similar. In a case this ratio is $1 / 100$ for $\mathrm{DMFc}^{+} / \mathrm{DMFc}$, 
(corresponding to $5 \mu \mathrm{M} \mathrm{H}_{2} \mathrm{O}_{2}$ and $10 \mu \mathrm{M} \mathrm{OH}^{-}$), and Galvani potential difference is 0 , the Fermi level of electrons in the nanofilm can be estimated as $-429 \mathrm{~kJ} / \mathrm{mol}$ ( or $-4.44 \mathrm{eV}$ ). Now the driving force for oxygen reduction is $298 \mathrm{mV}$ while the driving force for DMFc oxidation becomes $40 \mathrm{mV}$. Of course, these calculations give only approximate relations, as back-reaction for DMFc oxidation should not be neglected at such low overpotentials. Additionally, the rate equation for oxygen reduction used herein is probably too simple, even for alkaline conditions.

Metallization of the soft interface with AuNPs, as described herein, effectively allows the soft interface to mimic neutral $\mathrm{O}_{2}$ reduction at a conventional solid gold electrode, with DMFc acting at the electron source and the potential at the soft "electrode" surface being adjustable by manipulating $\Delta_{\mathrm{o}}^{\mathrm{w}} \phi$.

\section{CONCLUSIONS}

In summary, the interfacial redox catalysis of a key energy related reaction, the $\mathrm{O}_{2}$ reduction reaction, is demonstrated using a biphasic approach with $\mathrm{O}_{2}$ dissolved in the aqueous phase, the electron donor species dissolved in the organic phase and the soft interface functionalized with a conductive catalytic nanofilm of AuNPs. The utility of interfacial redox catalysis at functionalized soft interfaces as an ideal model system to probe catalytic reactions without the need for solid substrates is enabled by the ease of functionalization of the interface with solid conductive catalytic (nano)materials, the experimental flexibility provided by the solubility of reactants or products in either phase and the additional driving force provided by electrochemical polarisability of soft interfaces. In this regard new biphasic electrocatalytic pathways are expected to emerge with the soft interface allowing their facile interrogation by voltammetric and spectroscopic techniques.

\section{ACKNOWLEDGEMENTS}

The authors acknowledge the Swiss National Science Foundation for support (Grant: Solar Fuel 2000-20_152 557/1). This publication emanated from research by M.D.S. supported in part by a research grant from Science Foundation Ireland (SFI) under Grant Number 13/SIRG/2137. P.P. acknowledges the financial support from Fondazione Oronzio e Niccolò De Nora. 


\section{Appedix A. Standard transfer potentials of ions between water and trifluorotoluene}

The standard transfer potentials and energies of a group of ions were recalculated from the data presented in reference [54]. The standard transfer potentials of ions can be estimated from the experimental half-wave potential values from the following equation:

$$
\Delta_{\mathrm{o}}^{\mathrm{w}} \phi_{1 / 2}=\Delta_{\mathrm{o}}^{\mathrm{w}} \phi_{i}^{0}+\frac{R T}{z_{i} F} \ln \frac{\gamma_{i}^{\mathrm{o}}}{\gamma_{i}^{\mathrm{w}}}-\frac{R T}{z_{i} F} \ln \sqrt{\frac{D_{i}^{\mathrm{o}}}{D_{i}^{\mathrm{W}}}}
$$

As the diffusion coefficients of the species in the oil phase are difficult to determine experimentally, they can be estimated instead with Walden's rule [54], stating that

$$
\frac{D_{i}^{\mathrm{o}}}{D_{i}^{\mathrm{w}}}=\frac{\eta^{\mathrm{w}}}{\eta^{\mathrm{o}}}
$$

However, this relation is not completely accurate for ions in aqueous solvents due to strong hydration. The activity coefficients in Equation A1 can be estimated for example with the Debye-Hückel theory [54]. Following the calculations of ref. [54], but utilising a viscosity of $0.527 \mathrm{mPa} \mathrm{s}$ instead of $0.038 \mathrm{mPa} \mathrm{s}$ for TFT [55], and avoiding the sign error in the original paper, the resulting values are presented in the Table A1. The transfer energy is calculated as follows:

$$
\Delta_{\mathrm{o}}^{\mathrm{w}} \phi_{i}^{0}=\frac{\Delta G_{\mathrm{tr}, i}^{\mathrm{w} \rightarrow \mathrm{o}}}{z_{i} F}
$$

Table A1. The corrected standard transfer potentials and energies between water and TFT based on experimental half-wave potentials from ref. [54].

\begin{tabular}{|l|l|l|l|}
\hline Ion & $\Delta \phi_{1 / 2}, \mathrm{~V}$ & $\Delta \phi^{0}, \mathrm{~V}$ & $\Delta G_{\mathrm{tr}, i}^{\mathrm{W} \rightarrow \mathrm{TFT}}, \mathrm{kJ} \mathrm{mol}^{-1}$ \\
\hline $\mathrm{TPAs}^{+}$ & -0.2625 & -0.2189 & -21.12 \\
\hline $\mathrm{TPB}^{-}$ & 0.2625 & 0.2189 & -21.12 \\
\hline $\mathrm{TMA}^{+}$ & 0.2675 & 0.3111 & 30.01 \\
\hline
\end{tabular}




\begin{tabular}{|l|l|l|l|}
\hline TEA $^{+}$ & 0.1055 & 0.1491 & 14.38 \\
\hline TPropA $^{+}$ & -0.0215 & 0.0221 & 2.13 \\
\hline TBA $^{+}$ & -0.1485 & -0.1049 & -10.12 \\
\hline
\end{tabular}

Now these transfer energy values can be plotted as a function of corresponding transfer energies measured at water-1,2-dichloroethane interface [56] in Figure A1.

Figure A1. Linear dependence of transfer energies between DCE and TFT.

The equation of the line in Figure A1 was utilized to evaluate the standard transfer energy of protons from water to TFT, $\Delta G_{\operatorname{tr}, \mathrm{H}^{+}}^{0, \mathrm{TFT}}$, as $69 \mathrm{~kJ} \mathrm{~mol}^{-1}$ when and taking $\Delta G_{\mathrm{tr}, \mathrm{H}^{+}}^{0, \mathrm{DCE}}$ is $53 \mathrm{~kJ}$ $\mathrm{mol}^{-1}$ [56]. Unfortunately, the correlation of the standard transfer energies between DCE and TFT obtained by this method and by droplet electrodes [16] differ significantly. As these two data sets contain only three common ions, further measurements are required to confirm the standard transfer energies between water and TFT.

\section{Appendix B. Standard redox potentials of oxygen reduction in trifluorotoluene (TFT)}

The standard redox potentials of the oxygen reduction reactions in trifluorotoluene can be estimated with the thermodynamic cycle [56]. In general, the reduction of $\mathrm{O}$ to $\mathrm{R}$ in phase $\alpha$ is expressed as

$\mathrm{O}(\alpha)+n e^{-} \rightarrow \mathrm{R}(\alpha)$

where the standard redox potential can be expressed as [57]:

$$
\left[E_{\mathrm{O} / \mathrm{R}}^{0}\right]_{\mathrm{SHE}}^{\alpha}=-\frac{\Delta G^{0}}{n F}=\frac{1}{n F}\left(\mu_{\mathrm{O}}^{\circ, \alpha}-\mu_{\mathrm{R}}^{\circ, \alpha}-n\left(\mu_{\mathrm{H}^{+}}^{\circ, \mathrm{w}}-\frac{1}{2} \mu_{\mathrm{H}_{2}}^{\circ, \mathrm{w}}\right)\right)
$$


So, the standard redox potentials of the reaction (B1) in TFT and aqueous phase are

$$
\begin{aligned}
& {\left[E_{\mathrm{O} / \mathrm{R}}^{0}\right]_{\mathrm{SHE}}^{\mathrm{TFT}}=\frac{1}{n F}\left(\mu_{\mathrm{O}}^{\circ, \mathrm{TFT}}-\mu_{\mathrm{R}}^{\circ, \mathrm{TFT}}-n\left(\mu_{\mathrm{H}^{+}}^{\circ, \mathrm{w}}-\frac{1}{2} \mu_{\mathrm{H}_{2}}^{\circ, \mathrm{w}}\right)\right)} \\
& {\left[E_{\mathrm{O} / \mathrm{R}}^{0}\right]_{\mathrm{SHE}}^{\mathrm{w}}=\frac{1}{n F}\left(\mu_{\mathrm{O}}^{\circ, \mathrm{w}}-\mu_{\mathrm{R}}^{\circ, \mathrm{w}}-n\left(\mu_{\mathrm{H}^{+}}^{\circ, \mathrm{w}}-\frac{1}{2} \mu_{\mathrm{H}_{2}}^{\circ, \mathrm{w}}\right)\right)}
\end{aligned}
$$

When eq. (B3) is subtracted from eq. (B4), eq. (B5) is obtained:

$$
\begin{aligned}
& {\left[E_{\mathrm{O} / \mathrm{R}}^{0}\right]_{\mathrm{SHE}}^{\mathrm{TFT}}=\left[E_{\mathrm{O} / \mathrm{R}}^{0}\right]_{\mathrm{SHE}}^{\mathrm{w}}+\frac{1}{n F}\left(\mu_{\mathrm{O}}^{\circ, \mathrm{TFT}}-\mu_{\mathrm{R}}^{\circ, \mathrm{TFT}}-\mu_{\mathrm{O}}^{\mathrm{o}, \mathrm{w}}+\mu_{\mathrm{R}}^{\circ, \mathrm{w}}\right)=} \\
& {\left[E_{\mathrm{O} / \mathrm{R}}^{0}\right]_{\mathrm{SHE}}^{\mathrm{w}}+\frac{1}{n F}\left(\Delta_{\mathrm{o}}^{\mathrm{w}} G_{\mathrm{tr}, \mathrm{R}}^{0}-\Delta_{\mathrm{o}}^{\mathrm{w}} G_{\mathrm{tr}, \mathrm{O}}^{0}\right)}
\end{aligned}
$$

where $\Delta_{\mathrm{o}}^{\mathrm{w}} G_{\mathrm{i}}^{0}$ is the Gibbs energy of transfer of the species $i$ from oil phase to aqueous phase. Standard redox potentials of the following reactions in TFT were calculated with eq. (B5)

$$
\begin{aligned}
& \mathrm{H}^{+}+e^{-} \rightarrow 1 / 2 \mathrm{H}_{2} \\
& \mathrm{O}_{2}+2 \mathrm{H}^{+}+2 e^{-} \rightarrow \mathrm{H}_{2} \mathrm{O}_{2} \\
& 1 / 2 \mathrm{O}_{2}+2 \mathrm{H}^{+}+2 e^{-} \rightarrow \mathrm{H}_{2} \mathrm{O} \\
& {\left[E_{\mathrm{H}^{+} / \mathrm{H}_{2}}^{0}\right]_{\mathrm{SHE}}^{\mathrm{TFT}}=\left[E_{\mathrm{H}^{+} / \mathrm{H}_{2}}^{0}\right]_{\mathrm{SHE}}^{\mathrm{w}}+\frac{1}{F}\left(\Delta_{\mathrm{o}}^{\mathrm{w}} G_{\mathrm{H}_{2}}^{0}-\Delta_{\mathrm{o}}^{\mathrm{w}} G_{\mathrm{H}^{+}}^{0}\right)} \\
& {\left[E_{\mathrm{O}_{2} / \mathrm{H}_{2} \mathrm{O}_{2}}^{0}\right]_{\mathrm{SHE}}^{\mathrm{TFT}}=\left[E_{\mathrm{O}_{2} / \mathrm{H}_{2} \mathrm{O}_{2}}^{0}\right]_{\mathrm{SHE}}^{\mathrm{w}}+\frac{1}{2 F}\left(\Delta_{\mathrm{o}}^{\mathrm{w}} G_{\mathrm{H}_{2} \mathrm{O}_{2}}^{0}-\Delta_{\mathrm{o}}^{\mathrm{w}} G_{\mathrm{O}_{2}}^{0}-2 \Delta_{\mathrm{o}}^{\mathrm{w}} G_{\mathrm{H}^{+}}^{0}\right)} \\
& {\left[E_{\mathrm{O}_{2} / \mathrm{H}_{2} \mathrm{O}}^{0}\right]_{\mathrm{SHE}}^{\mathrm{TFT}}=\left[E_{\mathrm{O}_{2} / \mathrm{H}_{2} \mathrm{O}}^{0}\right]_{\mathrm{SHE}}^{\mathrm{w}}+\frac{1}{2 F}\left(\Delta_{\mathrm{o}}^{\mathrm{w}} G_{\mathrm{H}_{2} \mathrm{O}}^{0}-1 / 2 \Delta_{\mathrm{o}}^{\mathrm{w}} G_{\mathrm{O}_{2}}^{0}-2 \Delta_{\mathrm{o}}^{\mathrm{w}} G_{\mathrm{H}^{+}}^{0}\right)}
\end{aligned}
$$

In trifluorotoluene, $\Delta_{\mathrm{o}}^{\mathrm{w}} G_{\mathrm{H}^{+}}^{0}$ was estimated as $69 \mathrm{~kJ} / \mathrm{mol}$, and $\Delta G_{\mathrm{tr}, \mathrm{H}_{2} \mathrm{O}}^{0, \mathrm{wFT}}$ was estimated as 15.2 $\mathrm{kJ} \mathrm{mol}^{-1}$ from liquid-liquid equilibrium data between TFT, water and isopropanol from reference [46] assuming no excess molar volumes and utilising the lowest isopropanol concentration. $\Delta_{\mathrm{O}}^{\mathrm{w}} G_{\mathrm{H}_{2} \mathrm{O}_{2}}^{0}$ was estimated to be close to the value for $\Delta_{\mathrm{o}}^{\mathrm{w}} G_{\mathrm{H}_{2} \mathrm{O}}^{0}$. The final results are $\left[E_{2 \mathrm{H}^{+} / \mathrm{H}_{2}}^{0}\right]_{\mathrm{SHE}}^{\mathrm{TFT}}=0.717 \mathrm{~V},\left[E_{\mathrm{O}_{2} / \mathrm{H}_{2} \mathrm{O}_{2}}^{0}\right]_{\mathrm{SHE}}^{\mathrm{TFT}}=1.36 \mathrm{~V}$ and $\left[E_{\mathrm{O}_{2} / \mathrm{H}_{2} \mathrm{O}}^{0}\right]_{\mathrm{SHE}}^{\mathrm{TFT}}=1.91 \mathrm{~V}$, respectively, 
when transfer energies of gasses were considered to have little effect on the standard redox potential.

\section{Appendix C. Calculations of the Fermi Level of the Gold Nanofilm}

The Nernst equations for oxygen reduction to water and to $\mathrm{H}_{2} \mathrm{O}_{2}$ are

$$
\begin{aligned}
& {\left[E_{\mathrm{O}_{2} / \mathrm{H}_{2} \mathrm{O}}\right]_{\mathrm{SHE}}^{\mathrm{w}, \mathrm{pH} 7}=\left[E_{\mathrm{O}_{2} / \mathrm{H}_{2} \mathrm{O}}^{0}\right]_{\mathrm{SHE}}^{\mathrm{w}}+\frac{R T}{4 F} \ln \left(\frac{f_{\mathrm{O}_{2}}}{p^{0}}\right)+\frac{R T}{F} \ln \left(a_{\mathrm{H}^{+}}\right)} \\
& {\left[E_{\mathrm{O}_{2} / \mathrm{H}_{2} \mathrm{O}_{2}}\right]_{\mathrm{SHE}}^{\mathrm{w}, \mathrm{pH} 7}=\left[E_{\mathrm{O}_{2} / \mathrm{H}_{2} \mathrm{O}_{2}}^{0}\right]_{\mathrm{SHE}}^{\mathrm{w}}+\frac{R T}{2 F} \ln \left(\frac{f_{\mathrm{O}_{2}}}{p^{0}}\right)+\frac{R T}{F} \ln \left(a_{\mathrm{H}^{+}}\right)-\frac{R T}{2 F} \ln \left(a_{\mathrm{H}_{2} \mathrm{O}_{2}}\right)}
\end{aligned}
$$

and the Nernst equation for DMFc oxidation is

$$
\left[E_{\mathrm{DMFc}^{+} / \mathrm{DMFc}}\right]_{\mathrm{SHE}}^{\mathrm{o}}=\left[E_{\mathrm{DMFc}^{+} / \mathrm{DMFc}}^{0}\right]_{\mathrm{SHE}}^{\mathrm{o}}+\frac{R T}{F} \ln \left(\frac{a_{\mathrm{DMFc}^{+}}}{a_{\mathrm{DMFc}}}\right)
$$

If we consider that the Fermi level of electrons in the aqueous phase is determined by the $\mathrm{H}_{2} \mathrm{O}_{2} / \mathrm{O}_{2}$ redox couple and the Fermi level in the organic phase is determined by the $\mathrm{DMFc}^{+} / \mathrm{DMFc}$, and the positions of the Fermi levels can be calculated with equations 21 and 22 from the main text:

$$
E_{\mathrm{F}}^{\mathrm{w}}=-F\left[\left[E_{\mathrm{O}_{2} / \mathrm{H}_{2} \mathrm{O}_{2}}^{0}\right]_{\mathrm{SHE}}^{\mathrm{w}}+\frac{R T}{2 F} \ln \left(\frac{c_{\mathrm{O}_{2}}^{\mathrm{s}}}{c_{\mathrm{O}_{2}}^{p^{0}}}\right)+\frac{R T}{F} \ln \left(a_{\mathrm{H}^{+}}^{\mathrm{s}}\right)-\frac{R T}{2 F} \ln \left(a_{\mathrm{H}_{2} \mathrm{O}_{2}}^{\mathrm{s}}\right)+\phi_{\mathrm{w}}+\left[E_{\mathrm{H}^{+} / 1 / 2 \mathrm{H}_{2}}^{0}\right]_{\mathrm{AVS}}^{\mathrm{w}}\right]
$$

$$
E_{F}^{\mathrm{o}}=-F\left[\left[E_{\mathrm{DMFc}_{\mathrm{o}}^{+} / \mathrm{DMFc}_{\mathrm{o}}}^{0}\right]_{\mathrm{SHE}}^{\mathrm{o}}+\frac{R T}{F} \ln \left(\frac{a_{\mathrm{DMFc}_{\mathrm{o}}^{+}}^{s}}{a_{\mathrm{DMF}_{\mathrm{o}}^{0}}^{s}}\right)+\phi_{\mathrm{o}}+\left[E_{\mathrm{H}^{+} / 1 / 2 \mathrm{H}_{2}}^{0}\right]_{\mathrm{AVS}}^{\mathrm{w}}\right]
$$

Herein the fugacity and pressure of oxygen in equation $\mathrm{C} 2$ are changed to concentrations with Henry's law, so that $c_{\mathrm{O}_{2}}^{p^{0}}=1.28 \mathrm{mM}$ is the solubility of oxygen in water equilibrated with oxygen at a partial pressure of $1 \mathrm{~atm}$, and activity coefficient for oxygen is assumed as 1 .

Now we consider a case where we initially have $1 \mathrm{mM}$ of DMFc in the organic phase and $0.27 \mathrm{mM}$ of $\mathrm{O}_{2}$ in the aqueous phase at $\mathrm{pH}$ 7. If we assume that $1 \%$ of DMFc $(10 \mu \mathrm{M})$ is 
oxidized at the gold nanofilm, reducing $5 \mu \mathrm{M}$ of $\mathrm{O}_{2}$ into $\mathrm{H}_{2} \mathrm{O}_{2}$ and consuming $10 \mu \mathrm{M}$ of protons, assuming that this happens fast enough that negligible diffusion takes places the $\mathrm{pH}$ of the solution at the nanofilm surface changes to 9.00. The Nernst potentials at the nanofilm surfaces are then $0.299 \mathrm{~V} v s$. aqueous SHE in water side and $-0.038 \mathrm{~V}$ vs. aqueous SHE in the organic side, assuming that the effects of activity coefficients are negligible. Now the Fermi level of electrons in water and TFT can be calculated from equations $\mathrm{C} 4$ and $\mathrm{C} 5$ as $-457.2 \mathrm{~kJ} \mathrm{~mol}^{-1}$ and $-424.8 \mathrm{~kJ} \mathrm{~mol}^{-1}$ or -4.74 and $-4.40 \mathrm{eV}$, without the effect of the inner potentials. Now the Fermi level of electrons in the gold nanofilm can be estimated from equation 20 of the main text, as $-428.5 \mathrm{~kJ} \mathrm{~mol}^{-1}$ or $-4.44 \mathrm{eV}$ (neglecting the inner potentials). Now the driving forces for both reactions can be calculated from equations 23 and 24 of the main text:

$$
\begin{aligned}
& E_{\mathrm{F}}^{\mathrm{NP}}-E_{\mathrm{F}}^{\mathrm{w}} \approx \frac{F}{3}\left(\left[E_{\mathrm{O}_{2, \mathrm{w}} / \mathrm{H}_{2} \mathrm{O}_{2, \mathrm{w}}}\right]_{\mathrm{AVS}}^{\mathrm{w}}-\left[E_{\mathrm{DMFc}_{\mathrm{o}}^{+} / \mathrm{DMFc}_{\mathrm{o}}}\right]_{\mathrm{AVS}}^{\mathrm{o}}\right)+\frac{F\left(\phi_{\mathrm{w}}-\phi_{\mathrm{o}}\right)}{3}-\frac{2 R T}{3} \ln \left(2 \times 10^{-5}\right) \\
& E_{\mathrm{F}}^{\mathrm{o}}-E_{\mathrm{F}}^{\mathrm{NP}} \approx \frac{2 F}{3}\left(\left[E_{\mathrm{O}_{2} / \mathrm{H}_{2} \mathrm{O}_{2}}\right]_{\mathrm{AVS}}^{\mathrm{w}}-\left[E_{\mathrm{DMFc}^{+} / \mathrm{DMFc}}\right]_{\mathrm{AVS}}^{\mathrm{o}}\right)+\frac{2 F}{3}\left(\phi_{\mathrm{w}}-\phi_{\mathrm{o}}\right)+\frac{2 R T}{3} \ln \left(2 \times 10^{-5}\right)
\end{aligned}
$$

The driving force is $298 \mathrm{mV}$ for oxygen reduction and $39 \mathrm{mV}$ for DMFc oxidation. If the interface is polarized, $2 / 3$ of the additional driving force due to the Galvani potential difference goes to the organic phase. Interestingly, if we set the ratio $k_{\mathrm{w}}^{0} / k_{\mathrm{o}}^{0} \approx 1 \times 10^{-6}$, the driving force for the DMFc oxidation becomes negative at $0 \mathrm{~V}$ Galvani potential difference, and the aqueous phase needs to be polarized slightly positive to drive DMFc oxidation. Of course, this analysis does not take into account mass transport effects especially for the local $\mathrm{pH}$, and the backreaction for DMFc oxidation should not be neglected at such low overpotentials, but it works as a qualitative model to help to understand how the system works.

\section{REFERENCES}

[1] H. Duan, D. Wang, D.G. Kurth, H. Möhwald, Directing self-assembly of nanoparticles at water/oil interfaces, Angew. Chem. Int. Ed., 43 (2004) 5639-5642.

[2] Y.-K. Park, S.-H. Yoo, S. Park, Assembly of highly ordered nanoparticle monolayers at a water/hexane interface, Langmuir, 23 (2007) 10505-10510.

[3] V.A. Turek, M.P. Cecchini, J. Paget, A.R. Kucernak, A.A. Kornyshev, J.B. Edel, Plasmonic ruler at the liquid-liquid interface, ACS Nano, 6 (2012) 7789-7799.

[4] J.B. Edel, A.A. Kornyshev, M. Urbakh, Self-assembly of nanoparticle arrays for use as mirrors, sensors, and antennas, ACS Nano, 7 (2013) 9526-9532.

[5] P.-P. Fang, S. Chen, H. Deng, M.D. Scanlon, F. Gumy, H.J. Lee, D. Momotenko, V.

Amstutz, F. Cortés-Salazar, C.M. Pereira, Z. Yang, H.H. Girault, Conductive gold nanoparticle mirrors at liquid/liquid interfaces, ACS Nano, 7 (2013) 9241-9248. 
[6] M. Gadogbe, S.M. Ansar, I.W. Chu, S. Zou, D. Zhang, Comparative study of the selfassembly of gold and silver nanoparticles onto thiophene oil, Langmuir, 30 (2014) 11520-11527. [7] E. Smirnov, M.D. Scanlon, D. Momotenko, H. Vrubel, M.A. Méndez, P.-F. Brevet, H.H. Girault, Gold metal liquid-like droplets, ACS Nano, 8 (2014) 9471-9481.

[8] E. Smirnov, P. Peljo, M.D. Scanlon, H.H. Girault, Interfacial redox catalysis on gold nanofilms at soft interfaces, ACS Nano, 9 (2015) 6565-6575.

[9] B. Su, I. Hatay, F. Li, R. Partovi-Nia, M.A. Méndez, Z. Samec, M. Ersoz, H.H. Girault, Oxygen reduction by decamethylferrocene at liquid/liquid interfaces catalyzed by dodecylaniline, J. Electroanal. Chem., 639 (2010) 102-108.

[10] A.J. Olaya, P. Ge, J.F. Gonthier, P. Pechy, C. Corminboeuf, H.H. Girault, Four-electron oxygen reduction by tetrathiafulvalene, J. Am. Chem. Soc., 133 (2011) 12115-12123.

[11] H. Deng, P. Peljo, F. Cortés-Salazar, P. Ge, K. Kontturi, H.H. Girault, Oxygen and hydrogen peroxide reduction by 1,2-diferrocenylethane at a liquid/liquid interface, J. Electroanal. Chem., 681 (2012) 16-23.

[12] P. Peljo, L. Murtomäki, T. Kallio, H.-J. Xu, M. Meyer, C.P. Gros, J.-M. Barbe, H.H. Girault, K. Laasonen, K. Kontturi, Biomimetic oxygen reduction by cofacial porphyrins at a liquid-liquid interface, J. Am. Chem. Soc., 134 (2012) 5974-5984.

[13] Y. Gründer, M.D. Fabian, S.G. Booth, D. Plana, D.J. Fermín, P.I. Hill, R.A.W. Dryfe, Solids at the liquid-liquid interface: Electrocatalysis with pre-formed nanoparticles, Electrochim. Acta, 110 (2013) 809-815.

[14] J. Jedraszko, W. Nogala, W. Adamiak, E. Rozniecka, I. Lubarska-Radziejewska, H.H. Girault, M. Opallo, Hydrogen peroxide generation at liquid|liquid interface under conditions unfavorable for proton transfer from aqueous to organic phase, J. Phys. Chem. C, 117 (2013) 20681-20688.

[15] X. Liu, S. Wu, B. Su, Oxygen reduction with tetrathiafulvalene at liquid/liquid interfaces catalyzed by 5,10,15,20-tetraphenylporphyrin, J. Electroanal. Chem., 709 (2013) 26-30.

[16] W. Adamiak, J. Jedraszko, O. Krysiak, W. Nogala, J.C. Hidalgo-Acosta, H.H. Girault, M. Opallo, Hydrogen and hydrogen peroxide formation in trifluorotoluene-water biphasic systems, J. Phys. Chem. C, 118 (2014) 23154-23161.

[17] H. Deng, T.J. Stockmann, P. Peljo, M. Opallo, H.H. Girault, Electrochemical oxygen reduction at soft interfaces catalyzed by the transfer of hydrated lithium cations, J. Electroanal. Chem., 731 (2014) 28-35.

[18] S. Rastgar, H. Deng, F. Cortés-Salazar, M.D. Scanlon, M. Pribil, V. Amstutz, A.A.

Karyakin, S. Shahrokhian, H.H. Girault, Oxygen reduction at soft interfaces catalyzed by in situgenerated reduced graphene oxide, ChemElectroChem, 1 (2014) 59-63.

[19] T.J. Stockmann, H. Deng, P. Peljo, K. Kontturi, M. Opallo, H.H. Girault, Mechanism of oxygen reduction by metallocenes near liquid|liquid interfaces, J. Electroanal. Chem., 729 (2014) 43-52.

[20] I. Hatay, B. Su, F. Li, R. Partovi-Nia, H. Vrubel, X. Hu, M. Ersoz, H.H. Girault, Hydrogen evolution at liquid-liquid interfaces, Angew. Chem., 121 (2009) 5241-5244.

[21] I. Hatay, P.Y. Ge, H. Vrubel, X. Hu, H.H. Girault, Hydrogen evolution at polarised liquid/liquid interfaces catalyzed by molybdenum disulfide, Energy Environ. Sci., 4 (2011) 4246-4251.

[22] J.J. Nieminen, I. Hatay, P. Ge, M.A. Mendez, L. Murtomaki, H.H. Girault, Hydrogen evolution catalyzed by electrodeposited nanoparticles at the liquid/liquid interface, Chem. Commun., 47 (2011) 5548-5550.

[23] P. Ge, M.D. Scanlon, P. Peljo, X. Bian, H. Vubrel, A. O'Neill, J.N. Coleman, M. Cantoni, X. Hu, K. Kontturi, B. Liu, H.H. Girault, Hydrogen evolution across nano-Schottky junctions at carbon supported $\mathrm{MoS}_{2}$ catalysts in biphasic liquid systems, Chem. Commun., 48 (2012) 64846486. 
[24] X. Bian, M.D. Scanlon, S. Wang, L. Liao, Y. Tang, B. Liu, H.H. Girault, Floating conductive catalytic nano-rafts at soft interfaces for hydrogen evolution, Chem. Sci., 4 (2013) 3432-3441.

[25] P. Ge, A.J. Olaya, M.D. Scanlon, I. Hatay Patir, H. Vrubel, H.H. Girault, Photoinduced biphasic hydrogen evolution: decamethylosmocene as a light-driven electron donor, ChemPhysChem, 14 (2013) 2308-2316.

[26] M.D. Scanlon, X. Bian, H. Vrubel, V. Amstutz, K. Schenk, X. Hu, B. Liu, H.H. Girault, Low-cost industrially available molybdenum boride and carbide as "platinum-like" catalysts for the hydrogen evolution reaction in biphasic liquid systems, Phys. Chem. Chem. Phys., 15 (2013) 2847-2857.

[27] J. Jedraszko, W. Nogala, W. Adamiak, H.H. Girault, M. Opallo, Scanning electrochemical microscopy determination of hydrogen flux at liquid|liquid interface with potentiometric probe, Electrochem. Commun., 43 (2014) 22-24.

[28] E. Aslan, I.H. Patir, M. Ersoz, Cu nanoparticles electrodeposited at liquid-liquid interfaces: a highly efficient catalyst for the hydrogen evolution reaction, Chem. Eur. J., 21 (2015) 45854589.

[29] A.N.J. Rodgers, S.G. Booth, R.A.W. Dryfe, Particle deposition and catalysis at the interface between two immiscible electrolyte solutions (ITIES): A mini-review, Electrochem. Commun., 47 (2014) 17-20.

[30] I. Hatay Patir, Oxygen reduction catalyzed by aniline derivatives at liquid/liquid interfaces, J. Electroanal. Chem., 685 (2012) 28-32.

[31] Y. Li, S. Wu, B. Su, Proton-coupled $\mathrm{O}_{2}$ reduction reaction catalysed by cobalt phthalocyanine at liquid/liquid interfaces, Chem. Eur. J., 18 (2012) 7372-7376.

[32] A.J. Olaya, D. Schaming, P.-F. Brevet, H. Nagatani, H.-J. Xu, M. Meyer, H.H. Girault, Interfacial self-assembly of water-soluble cationic porphyrins for the reduction of oxygen to water, Angew. Chem. Int. Ed., 51 (2012) 6447-6451.

[33] A.J. Olaya, D. Schaming, P.-F. Brevet, H. Nagatani, T. Zimmermann, J. Vanicek, H.-J. Xu, C.P. Gros, J.-M. Barbe, H.H. Girault, Self-assembled molecular rafts at liquid|liquid interfaces for four-electron oxygen reduction, J. Am. Chem. Soc., 134 (2012) 498-506.

[34] M.D. Scanlon, P. Peljo, M.A. Mendez, E. Smirnov, H.H. Girault, Charging and discharging at the nanoscale: Fermi level equilibration of metallic nanoparticles, Chem. Sci., 6 (2015) 27052720.

[35] P.S. Toth, A.N.J. Rodgers, A.K. Rabiu, R.A.W. Dryfe, Electrochemical activity and metal deposition using few-layer graphene and carbon nanotubes assembled at the liquid-liquid interface, Electrochem. Commun., 50 (2015) 6-10.

[36] P.S. Toth, Q.M. Ramasse, M. Velicky, R.A.W. Dryfe, Functionalization of graphene at the organic/water interface, Chem. Sci., 6 (2015) 1316-1323.

[37] P.S. Toth, M. Velický, Q.M. Ramasse, D.M. Kepaptsoglou, R.A.W. Dryfe, Symmetric and asymmetric decoration of graphene: bimetal-graphene sandwiches, Adv. Funct. Mater., 25 (2015) 2899-2909.

[38] D.J. Fermin, H. Dung Duong, Z. Ding, P.-F. Brevet, H.H. Girault, Photoinduced electron transfer at liquid/liquid interfaces Part II. A study of the electron transfer and recombination dynamics by intensity modulated photocurrent spectroscopy (IMPS), Phys. Chem. Chem. Phys., 1 (1999) 1461-1467.

[39] J. Turkevich, P.C. Stevenson, J. Hillier, A study of the nucleation and growth processes in the synthesis of colloidal gold, Discuss. Faraday Soc., 11 (1951) 55-75.

[40] G. Frens, Controlled nucleation for the regulation of the particle size in monodisperse gold suspensions, Nat. Phys. Sci., 241 (1973) 20-22.

[41] H. Hotta, N. Akagi, T. Sugihara, S. Ichikawa, T. Osakai, Electron-conductor separating oilwater (ECSOW) system: a new strategy for characterizing electron-transfer processes at the oil/water interface, Electrochem. Commun., 4 (2002) 472-477. 
[42] P. Peljo, T. Rauhala, L. Murtomäki, T. Kallio, K. Kontturi, Oxygen reduction at a water1,2-dichlorobenzene interface catalyzed by cobalt tetraphenyl porphyrine - A fuel cell approach, Int. J. Hydrogen Energy, 36 (2011) 10033-10043.

[43] H. Deng, P. Peljo, T.J. Stockmann, L. Qiao, T. Vainikka, K. Kontturi, M. Opallo, H.H.

Girault, Surprising acidity of hydrated lithium cations in organic solvents, Chem. Commun., 50 (2014) 5554-5557.

[44] B. Su, I. Hatay, A. Trojánek, Z. Samec, T. Khoury, C.P. Gros, J.-M. Barbe, A. Daina, P.-A. Carrupt, H.H. Girault, Molecular electrocatalysis for oxygen reduction by cobalt porphyrins adsorbed at liquid/liquid interfaces, J. Am. Chem. Soc., 132 (2010) 2655-2662.

[45] A. Trojánek, J. Langmaier, Z. Samec, Thermodynamic driving force effects in the oxygen reduction catalyzed by a metal-free porphyrin, Electrochim. Acta, 82 (2012) 457-462.

[46] Z. Atik, M. Chaou, Solubilities and phase equilibria for ternary solutions of $\alpha, \alpha, \alpha-$ trifluorotoluene, water, and 2-propanol at three temperatures and pressure of $101.2 \mathrm{kPa}$, J. Chem. Eng. Data, 52 (2007) 932-935.

[47] R. Battino, T.R. Rettich, T. Tominaga, The Solubility of Oxygen and Ozone in Liquids, J. Phys. Chem. Ref. Data, 12 (1983) 163-178.

[48] P. Luehring, A. Schumpe, Gas solubilities (hydrogen, helium, nitrogen, carbon monoxide, oxygen, argon, carbon dioxide) in organic liquids at 293.2 K, J. Chem. \& Eng. Data, 34 (1989)

250-252.

[49] P. Quaino, N.B. Luque, R. Nazmutdinov, E. Santos, W. Schmickler, Why is Gold such a Good Catalyst for Oxygen Reduction in Alkaline Media?, Angew. Chem. Int. Ed., 51 (2012) 12997-13000.

[50] P. Rodriguez, M.T.M. Koper, Electrocatalysis on gold, Phys. Chem. Chem. Phys., 16 (2014) 13583-13594.

[51] M. Zhou, Y. Yu, K. Hu, M.V. Mirkin, Nanoelectrochemical Approach To Detecting ShortLived Intermediates of Electrocatalytic Oxygen Reduction, J. Am. Chem. Soc., 137 (2015) 65176523.

[52] M.T.M. Koper, Theory of multiple proton-electron transfer reactions and its implications for electrocatalysis, Chem. Sci., 4 (2013) 2710-2723.

[53] V.M. Fomin, A.A. Terekhina, K.S. Zaitseva, Mechanism of the reaction of 1,1'diethylferrocene and decamethylferrocene with peroxides in organic solvents, Russ. J. Gen. Chem., 83 (2013) 2324-2330.

[54] B.P. Binks, Particles as surfactants-similarities and differences, Curr. Opinion Colloid Interface Sci., 7 (2002) 21-41.

[55] F. Reincke, S.G. Hickey, W.K. Kegel, D. Vanmaekelbergh, Spontaneous Assembly of a Monolayer of Charged Gold Nanocrystals at the Water/Oil Interface, Angew. Chem. Int. Ed., 43 (2004) 458-462. 
(A)

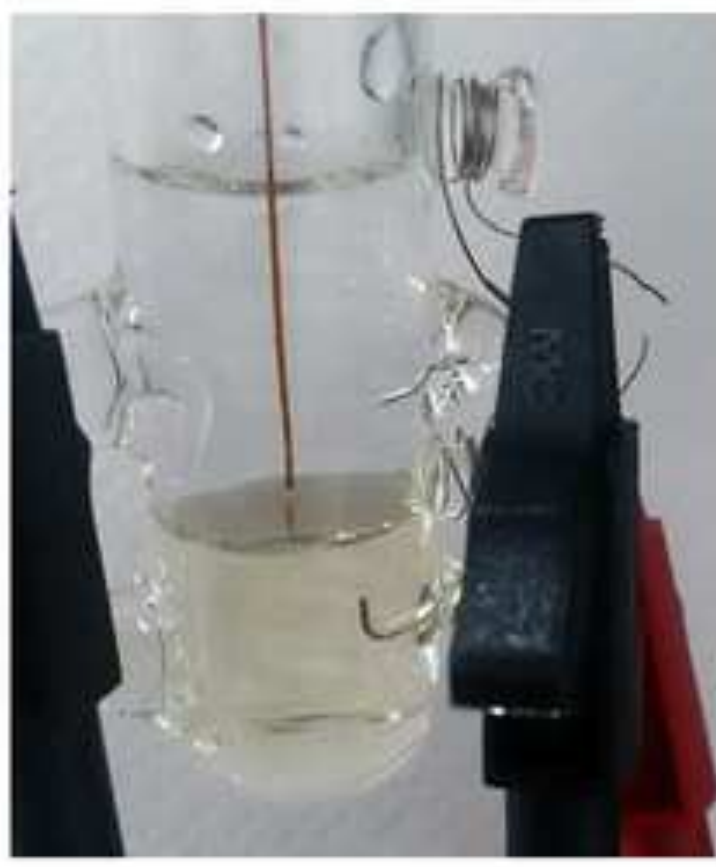

(B)

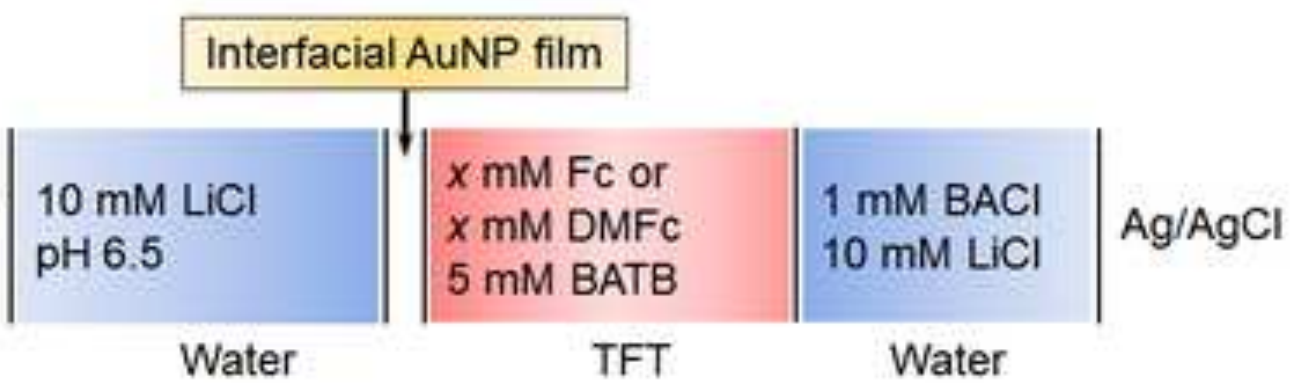

(C)

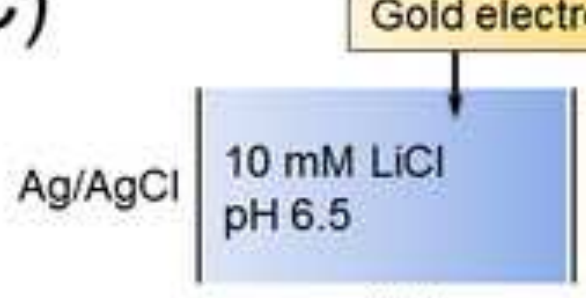

Water

(D)
Water

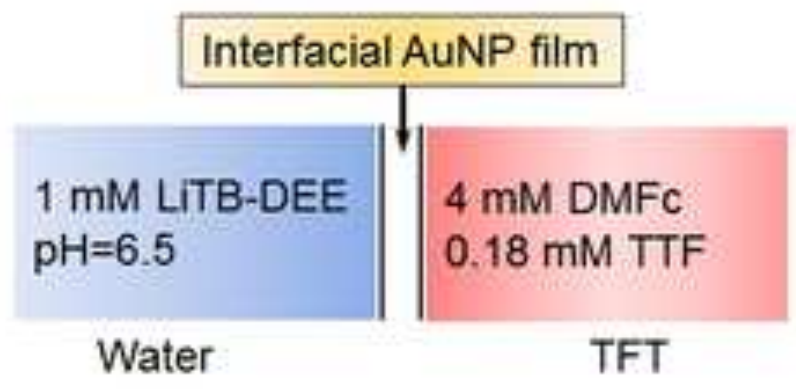




\section{Anaerobic conditions}

0
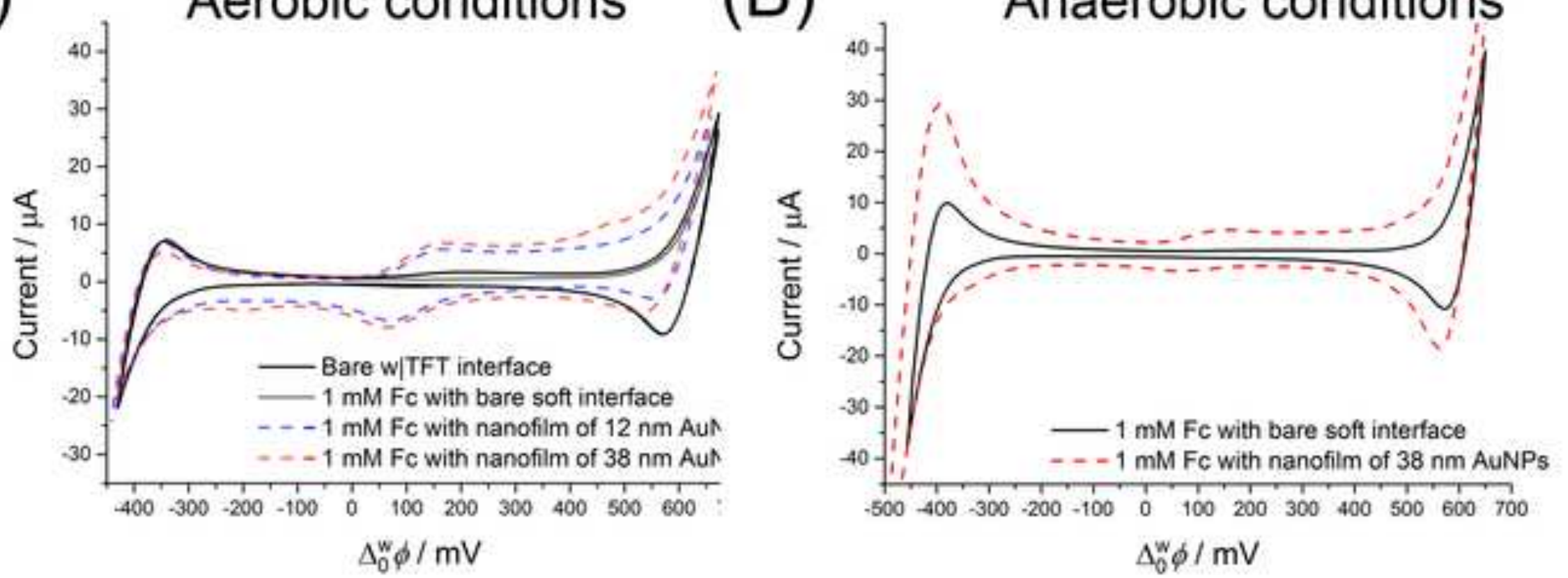

(C)

(D)
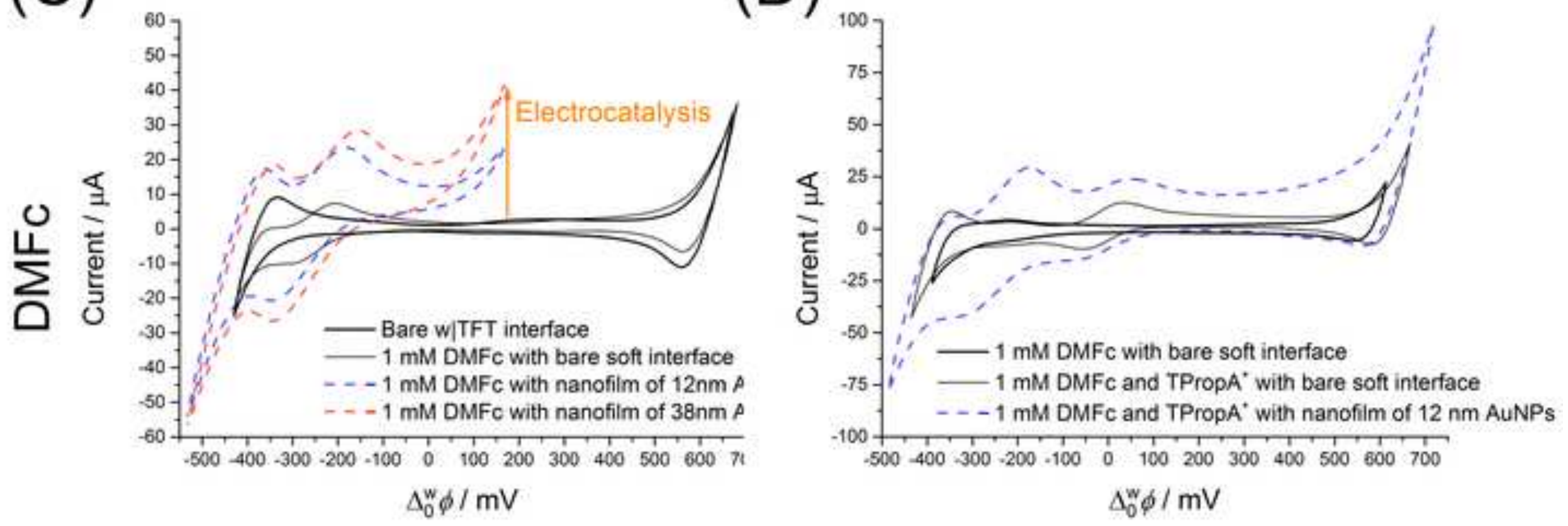


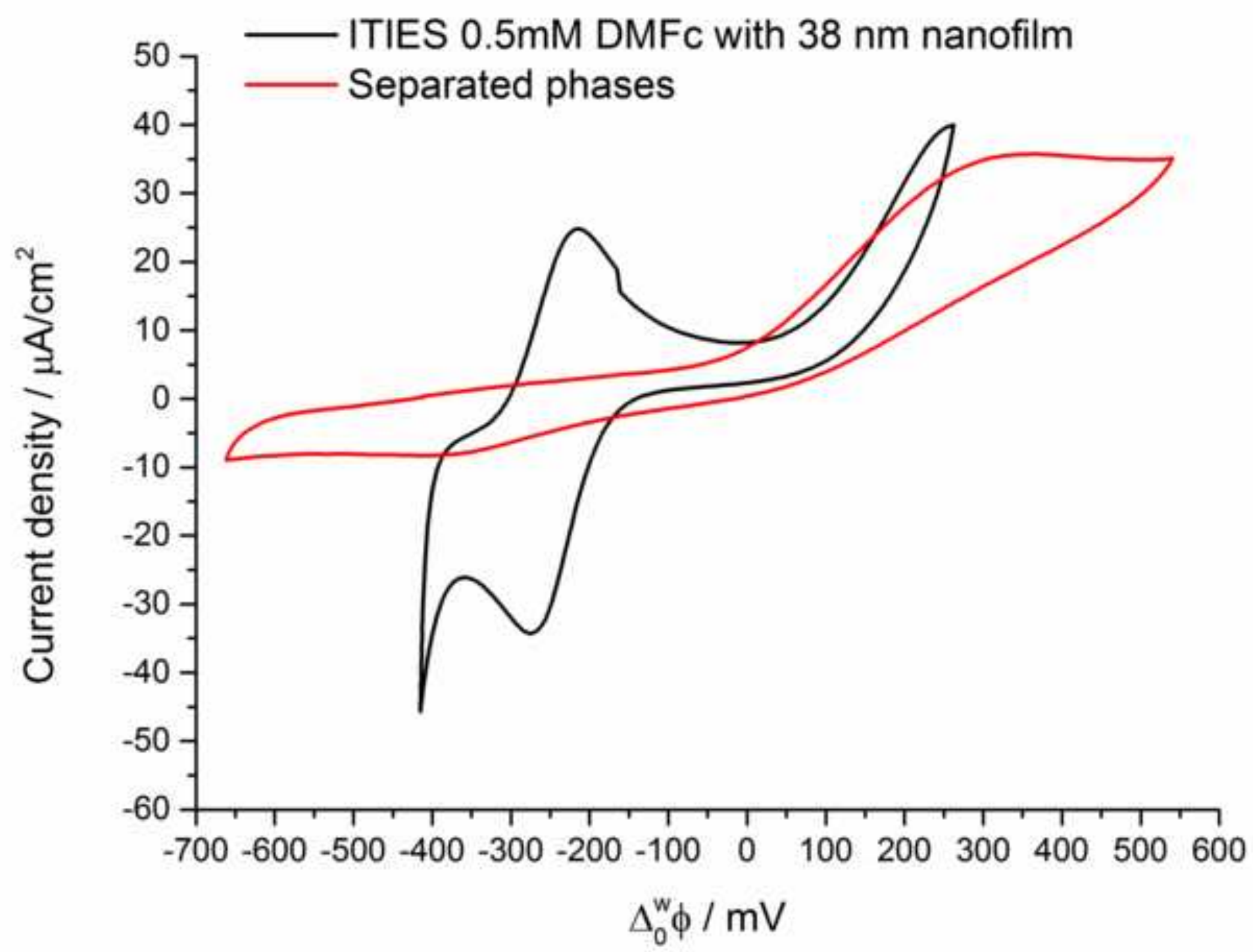




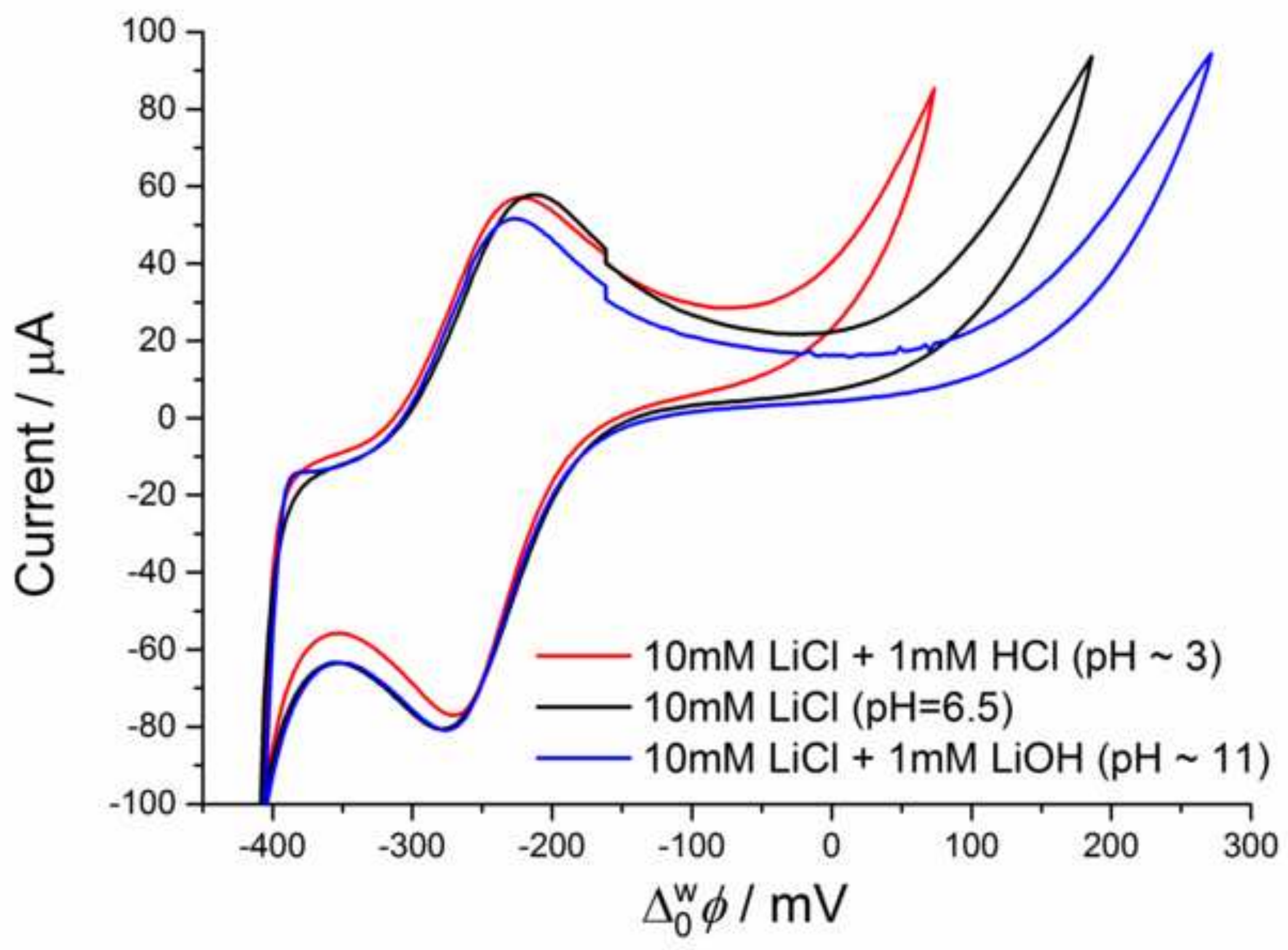




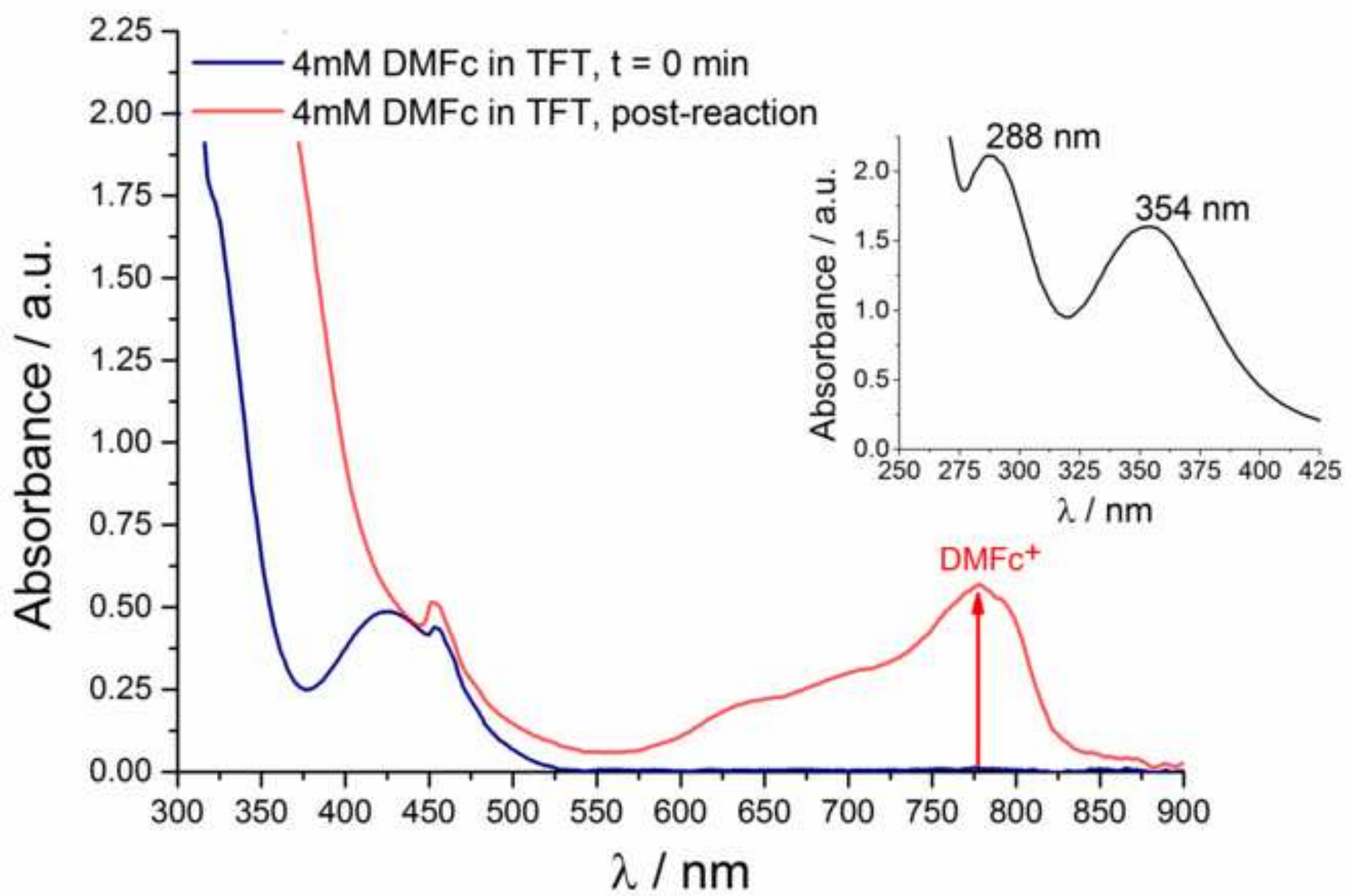




\section{Aqueous phase}

NP discharging

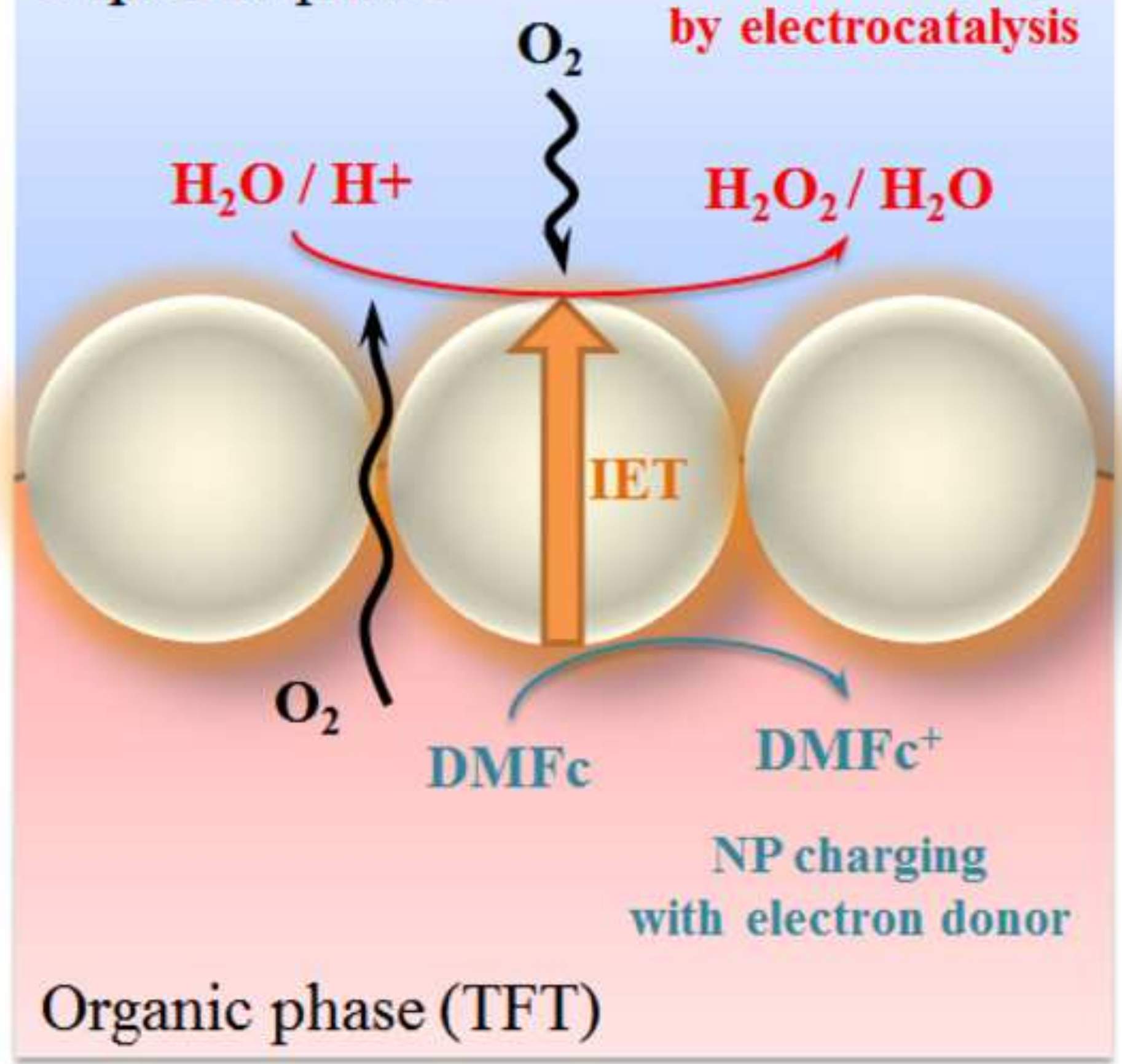

\section{$\mathrm{H}_{2} \mathrm{O}_{2} / \mathrm{H}_{2} \mathrm{O}$}

$\mathrm{O}_{2}$

$\mathrm{DMFc}^{+}$

NP charging with electron donor

\section{Organic phase (TFT)}




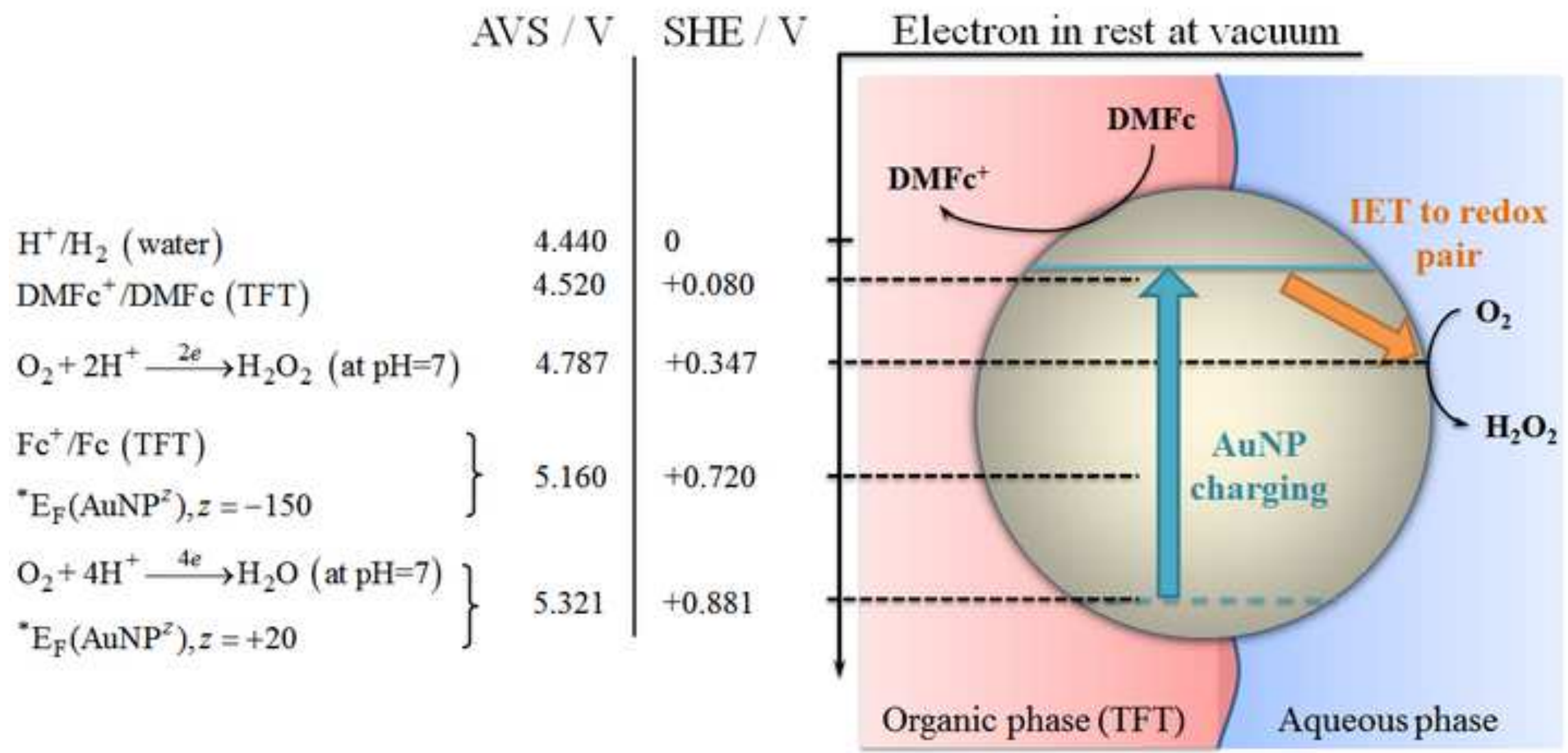

Values of $\mathrm{E}_{\mathrm{F}}$ were calculated in accordance with previously published theoretical model $[8,34]$ 


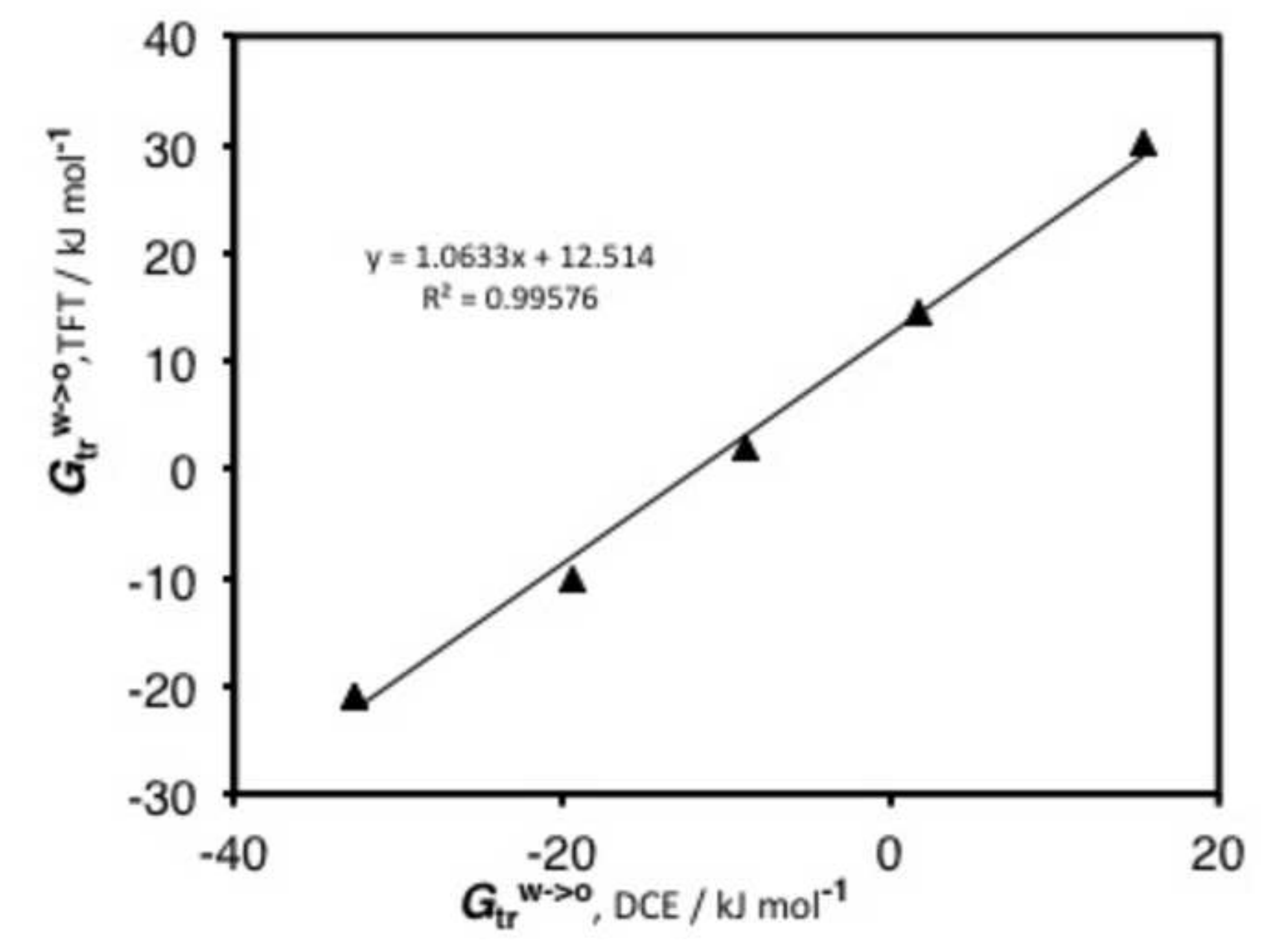



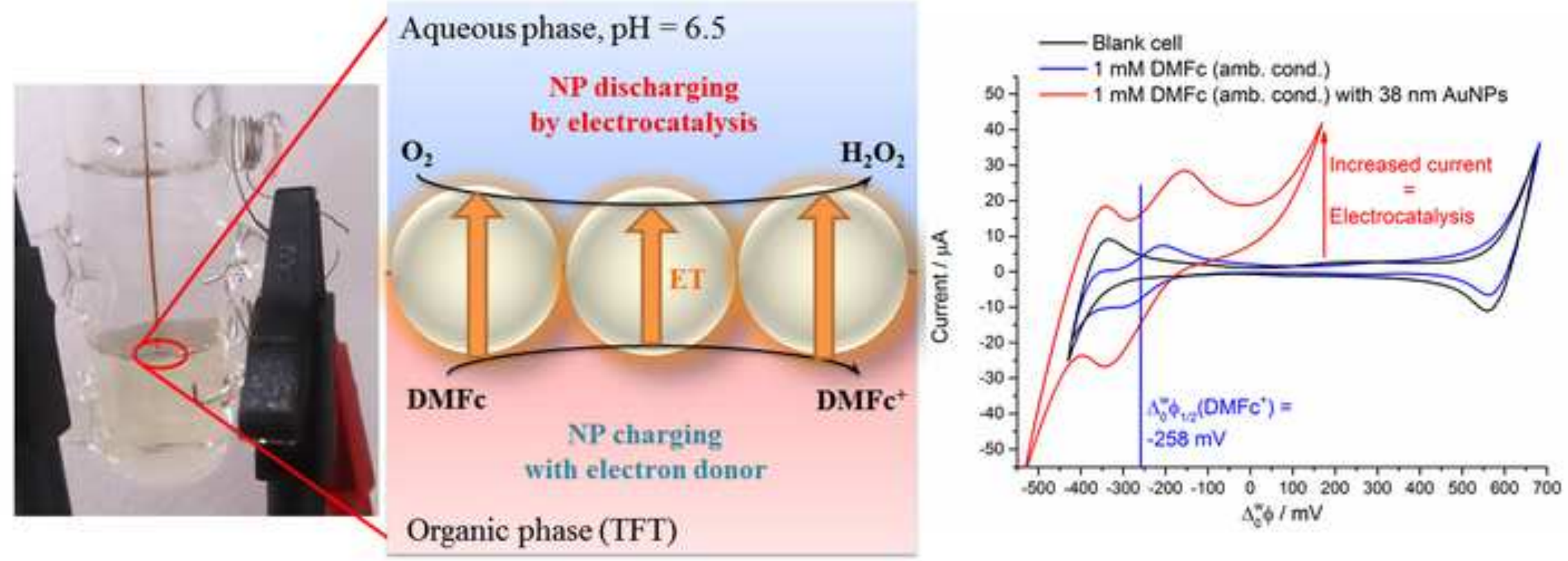